\title{
The X-Linked Intellectual Disability Protein IL1RAPL1 Regulates Dendrite Complexity
}

\author{
[CCaterina Montani, ${ }^{1,2}{ }^{\circledR}$ Mariana Ramos-Brossier, ${ }^{3}$ Luisa Ponzoni, ${ }^{2,4}$ - $L a u r a$ Gritti, ${ }^{1,2}$ Andrzej W. Cwetsch, ${ }^{5}$ \\ -Daniela Braida, ${ }^{2}$ Yoann Saillour, ${ }^{3}$ Benedetta Terragni, ${ }^{6}{ }^{\circledR}$ Massimo Mantegazza, ${ }^{7,8}$ @Mariaelvina Sala, ${ }^{1,2}$ \\ (C)Chiara Verpelli, ${ }^{1,2}$ DPierre Billuart, ${ }^{3}$ and $\mathbb{C}$ Carlo Sala ${ }^{1,2}$ \\ ${ }^{1}$ National Research Council Neuroscience Institute, 20129 Milan, Italy, ${ }^{2}$ Department of Medical Biotechnology and Translational Medicine, Università degli \\ Studi di Milano, 20129 Milan, Italy, ${ }^{3}$ Institut Cochin, Institut national de la santé et de la recherche médicale U1016, Centre National de la Recherche \\ Scientifique UMR8104, Université Paris Descartes, Paris 75014, France, ${ }^{4}$ Fondazione Umberto Veronesi, 20122 Milan, Italy, ${ }^{5}$ Department of Neuroscience \\ and Brain Technologies, Istituto Italiano di Tecnologia, 16163 Genoa, Italy, ${ }^{6}$ Operating Unit of Neurophysiopathology and Diagnostic Epileptology, \\ Foundation Istituto di Ricerca e Cura a Carattere Scientifico Neurological Institute Carlo Besta, 20133 Milan, Italy, ${ }^{7}$ Institute of Molecular and Cellular \\ Pharmacology, Laboratory of Excellence in Ion Channel Science and Therapeutics, Centre National de la Recherche Scientifique UMR7275, 06560 Valbonne, \\ France, and ${ }^{8}$ Université Côte d'Azur, 06560 Valbonne, France
}

Mutations and deletions of the interleukin-1 receptor accessory protein like 1 (IL1RAPL1) gene, located on the X chromosome, are associated with intellectual disability (ID) and autism spectrum disorder (ASD). IL1RAPL1 protein is located at the postsynaptic compartment of excitatory synapses and plays a role in synapse formation and stabilization. Here, using primary neuronal cultures and Ill rapll-KO mice, we characterized the role of IL1RAPL1 in regulating dendrite morphology. In Ill rapl1-KO mice we identified an increased number of dendrite branching points in CA1 and CA2 hippocampal neurons associated to hippocampal cognitive impairment. Similarly, induced pluripotent stem cell-derived neurons from a patient carrying a null mutation of the IL1RAPL1 gene had more dendrites. In hippocampal neurons, the overexpression of full-length IL1RAPL1 and mutants lacking part of C-terminal domains leads to simplified neuronal arborization. This effect is abolished when we overexpressed mutants lacking part of N-terminal domains, indicating that the IL1RAPL1 extracellular domain is required for regulating dendrite development. We also demonstrate that PTP $\delta$ interaction is not required for this activity, while IL1RAPL1 mediates the activity of IL-1 $\beta$ on dendrite morphology. Our data reveal a novel specific function for IL1RAPL1 in regulating dendrite morphology that can help clarify how changes in IL1RAPL1-regulated pathways can lead to cognitive disorders in humans.

Key words: dendrites; hippocampus; human iPS cells; IL1- $\beta$; synapses; X-linked ID

Significance Statement

Abnormalities in the architecture of dendrites have been observed in a variety of neurodevelopmental, neurodegenerative, and neuropsychiatric disorders. Here we show that the X-linked intellectual disability protein interleukin-1 receptor accessory protein like 1 (IL1RAPL1) regulates dendrite morphology of mice hippocampal neurons and induced pluripotent stem cell-derived neurons from a patient carrying a null mutation of IL1RAPL1 gene. We also found that the extracellular domain of IL1RAPL1 is required for this effect, independently of the interaction with PTP $\delta$, but IL1RAPL1 mediates the activity of IL-1 $\beta$ on dendrite morphology. Our data reveal a novel specific function for IL1RAPL1 in regulating dendrite morphology that can help clarify how changes in IL1RAPL1-regulated pathways can lead to cognitive disorders in humans.

\section{Introduction}

Intellectual disability (ID), which affects $\sim 2 \%$ of the population in industrialized countries, can be defined by three main criteria: intelligent quotient $<70$, autism spectrum disorders

Received Dec. 9, 2016; revised March 17, 2017; accepted May 4, 2017

Author contributions: C.M., C.V., P.B., and C.S. designed research; C.M., M.R.-B., L.P., L.G., A.W.C., D.B., Y.S., and

B.T. performed research; M.M., M.S., and P.B. contributed unpublished reagents/analytic tools; C.M., M.R.-B., L.P.,

L.G., B.T., and C.V. analyzed data; C.M., M.R.-B., M.S., P.B., and C.S. wrote the paper.
(ASDs) or other deficits in adaptive behavior, and onset before 18 years old.

Severe forms of ID are attributable to mutations of a single gene on the X chromosome (Chechlacz and Gleeson, 2003; Hayashi et al., 
2009). Among them, interleukin-1 receptor accessory protein like 1 (IL1RAPL1) gene has been found mutated in patients with cognitive impairments ranging from nonsyndromic ID to ASD (Ramos-Brossier et al., 2015). IL1RAPL1 protein belongs to the Toll/IL-1 receptor family and is structurally formed by three extracellular Ig-like domains, a transmembrane domain, and an intracellular Toll/IL-1R homology domain.

In vitro, IL1RAPL1 plays a role in presynaptic differentiation and in dendritic spine formation and stabilization in cortical and hippocampal neurons (Pavlowsky et al., 2010a; Valnegri et al., 2011a; Yoshida et al., 2011; Sala and Segal, 2014; Ramos-Brossier et al., 2015). The IL1RAPL1 C terminus interacts with the neuronal calcium sensor-1 regulating-type voltage-gated calcium channel activity in PC12 cells and in neurons (Gambino et al., 2007). Moreover, IL1RAPL1 regulates the synaptic localization of PSD-95 by controlling c-Jun terminal kinase (JNK) activity and PSD-95 phosphorylation (Pavlowsky et al., 2010a). The C-terminal tail of IL1RAPL1 can also recruit RhoGAP2. Meanwhile, the extracellular domain can bind to receptor tyrosine phosphatase $\delta(\mathrm{PTP} \delta)$, a member of the LAR-RPTP (leucocyte common antigen-related receptor protein tyrosine phosphatase) family (Valnegri et al., 2011a). The interaction of IL1RAPL1 with RhoGAP2 is required to induce dendritic spine formation and blocking the IL1RAPL1/ PTP $\delta$ interaction abolished RhoGAP2 recruitment at excitatory synapses, suggesting that IL1RAPL1 is involved in a transsynaptic signaling pathway (Valnegri et al., 2011a). IL1RAPL1, through the Mcf2l-RhoA-ROCK signaling pathway, can also regulate the formation and stabilization of glutamatergic synapses among cortical neurons (Hayashi et al., 2013).

Two independent Ill rapl1-KO mice were generated and studied for some molecular and behavioral features. In these mice, the loss of Illrapl1 led to a reduction of spine density in the cortex (Yasumura et al., 2014) and, in the CA1 region of the hippocampus, (Pavlowsky et al., 2010a; Yasumura et al., 2014), altered local excitation-inhibition balance in the cerebellum and amygdala (Gambino et al., 2009; Houbaert et al., 2013). These molecular and functional alterations are associated with deficits in spatial memory (Yasumura et al., 2014), altered cued fear-memory formation (Houbaert et al., 2013) and impaired acquisition and retention of spatial reference memory, spatial working memory, and long-term fear memories (Yasumura et al., 2014). However, in one of the two mouse lines, social interaction increased and motor coordination improved (Yasumura et al., 2014). These mice also demonstrated enhanced locomotor activity and reduced anxiety-like behaviors (Yasumura et al., 2014).

Because all these behavioral and electrophysiological alterations might be not fully explained by the altered excitatory synapse formation, we looked at the potential role of IL1RAPL1 in regulating dendrite morphology using a Ill rapl1-KO mice, that we better characterize for behavioral alterations. We also studied induced pluripotent stem (iPS) cell-derived neurons from a patient carrying a null mutation of the IL1RAPL1 gene. Interestingly we found that IL1RAPL1 regulates dendrite morphology modulating the activity of IL- $1 \beta$.

Fondazione Cariplo (Project 2013-08793). P.B. was supported by the European Union's FP7 large-scale integrated network Gencodys (http://www.gencodys.eu/, HEALTH-241995), the French Research Agency (ANR-2010-BLANC1434-03), the European Union's EraNet program (ANR 2010-Neuro-001-01), and the Institut national de la santé et de la recherche médicale (INSERM). M.R.-B. was supported by Ecole des Neurosciences de Paris and Fondation EDF. The authors declare no competing financial interests.

Correspondence should be addressed to Carlo Sala, Consiglio Nazionale delle Ricerche Neuroscience Institute, Via Vanvitelli, 32, 20129 Milano, Italy. E-mail: c.sala@in.cnr.it.

DOI:10.1523/JNEUROSCI.3775-16.2017

Copyright $\odot 2017$ the authors $\quad 0270-6474 / 17 / 376607-22 \$ 15.00 / 0$

\section{Materials and Methods}

\section{Animals}

To prepare primary neuronal rat cultures, pregnant Sprague Dawley female rats (Rattus norvegicus) were purchased from Charles River Laboratories. For the in utero electroporation experiment, cd1 mice were used (Charles River Laboratories). Il1 rapl1-KO mice (ill rapl1 ${ }^{\text {tm1.1Hesk, }}$ Il1 rapl1-KO), presenting with a deletion of the fifth exon, were derived on a C57BL/6 background (Charles River Laboratories) as described previously (Gambino et al., 2009). Mice and rats were housed under constant temperature $\left(22 \pm 1^{\circ} \mathrm{C}\right)$ and humidity $(50 \%)$ conditions with a $12 \mathrm{~h} \mathrm{light/dark} \mathrm{cycle,} \mathrm{and} \mathrm{were} \mathrm{provided} \mathrm{with} \mathrm{food} \mathrm{and} \mathrm{water} \mathrm{ad} \mathrm{libitum.}$

All experiments involving animals followed guidelines established by the European Communities Council and the Italian Ministry of Health (Rome, Italy). Experimental procedures of behavioral analysis followed the guidelines established by the Italian Council on Animal Care and were approved by the Italian Government Decree No. 17/2013. All efforts were made to minimize the number of subjects used and their suffering.

For genotyping of mice, DNA was extracted from tails and analyzed by PCR with the REDExtract-N-AmpTM Tissue PCR Kit (Sigma-Aldrich).

\section{Behavioral assays}

For behavioral analysis, 3-month-old age-matched littermate mice were used. All the experimental procedures followed the guidelines established by the Italian Council on Animal Care and were approved by the Italian government. Illrapl1-KO mice and their littermates were housed in cages, in groups of five, with ad libitum access to food and water at $22^{\circ} \mathrm{C}$ and with a $12 \mathrm{~h}$ alternating light/dark cycle. For behavioral profile, animals were tested once for each test. All the tests were performed between 8:00 A.M. and 2:00 P.M. All behavioral tests were performed between 9:00 A.M. and 1:00 P.M. Multiple cohorts were used. Mice in Cohort 1 were weekly tested for anxiety (in the elevated plus maze), motor activity, and sociability/social novelty. They were also tested in the Morris water maze. Mice in Cohort 2 were weekly tested for marble-burying behavior, self-grooming, olfactory behavior, and novel-object recognition. They were also tested in the radial maze. Mice in Cohort 3 were observed in tests involving novelty suppressed feeding, nest building, and the T maze. Mice in Cohort 4 were tested only for fear conditioning. Mice in Cohort 5 were tested for conditioned taste aversion, aggression, and passive avoidance. Between the nonstress experiments (emotional-like behavior, self-grooming, motor function, object recognition) and the different maze tasks, there was an interval of 2 weeks. For each test $8-10$ mice were used.

Elevated plus maze. The elevated plus maze test was performed as described previously (Braida et al., 2007). The apparatus consisted of two opposite open arms $(35 \times 10 \mathrm{~cm})$ and two enclosed arms $(35 \times 10 \mathrm{~cm})$ extended from a common central platform $(10 \times 10 \mathrm{~cm})$. Animals were moved to the plus maze laboratory to facilitate adaptation to novel surroundings for $20 \mathrm{~min}$. Then, mice were placed individually onto the center of the apparatus facing an open arm. The time spent in each arm and the number of entries into each arm were noted for $5 \mathrm{~min}$ by a trained observer who remained unaware of the treatments. The maze was wiped clean with water and dried after each trial. An arm entry was recorded when all four paws of the mouse were in the arm. The number of openarm entries and the time spent in open arms were recorded and expressed as percentages (open entries/total entries $\times 100$; open time/total time $\times$ 100).

Marble-burying test. The marble-burying test uses spontaneous digging behavior, characteristic of rodents, to assess anxiety-like/compulsive behavior (Turner et al., 2010). After acclimation (1 h) in the test room, each mouse was placed in a cage $(26 \times 20 \times 14 \mathrm{~cm})$ for $30 \mathrm{~min}$ for habituation. Then, each mouse was removed and 20 marbles were distributed equally on top of mouse bedding ( $5 \mathrm{~cm}$ in depth). Each mouse was placed again in the cage for $15 \mathrm{~min}$. The buried marbles were counted and the latency to the burial of the first marble was measured.

Novelty suppressed feeding test. Animals were food-deprived for $24 \mathrm{~h}$ before the test (Mosienko et al., 2012). The latency to the first eating episode (time between introduction to the arena with food pellet in the middle and the first feeding event) was used as an index of induced anxiety-like behavior. The amount of food intake in the home cage dur- 
ing the subsequent ad libitum feed for 5 min provided a measure of appetitive drive.

Spontaneous motor activity. Motor function was evaluated in an activity cage $(43 \times 43 \times 32 \mathrm{~cm}$; Ugo Basile) placed in a sound-attenuating room, as previously described (Sala et al., 2011). The cage was fitted with two parallel horizontal and vertical infrared beams located 2 and $4 \mathrm{~cm}$ from the floor, respectively. Before the start of the test, each mouse was habituated to the testing room for $1 \mathrm{~h}$. Cumulative horizontal and vertical movement counts were recorded every hour for $4 \mathrm{~h}$.

Nest building. The nest-building test was performed in the home cage. Each cage was supplied with a "nestlet," a $5 \mathrm{~cm}$ square of pressed cotton batting, $1 \mathrm{~h}$ before the dark phase (Deacon, 2006). Results were assessed the next morning. The nests were assessed on a five-point scale: 1 , the nestlet is largely untouched ( $>90 \%$ intact); 2 , the nestlet is partially torn up (50-90\% remaining intact); 3 , the nestlet is mostly shredded but nest site is possibly not identifiable: $<50 \%$ of the nest remains intact but $<90 \%$ is within a quarter of the cage floor area, i.e., the cotton is not gathered into a nest but spread around the cage (note: the material may sometimes be in a broadly defined nest area but the critical definition is that $50-90 \%$ has been shredded); 4 , an identifiable, but flat nest: $>90 \%$ of the nestlet is torn up; the material is gathered into a nest within a quarter of the cage floor area, but the nest is flat, with walls higher than mouse body height (curled up on its side) on $<50 \%$ of its circumference; 5 , a (near) perfect nest: $>90 \%$ of the nest is torn up; the nest is a crater, with walls higher than mouse body height on $>50 \%$ of its circumference.

This procedure was repeated each day for 4 consequent days. Data were shown in terms of score and the calculated area under the curve (AUC).

Repetitive self-grooming. Spontaneous repetitive self-grooming behavior was scored as previously described (McFarlane et al., 2008). Each mouse was individually placed into a standard cylinder $(46 \mathrm{~cm}$ length $X$ $23.5 \mathrm{~cm}$ wide $\times 20 \mathrm{~cm}$ high). Cylinders were empty to eliminate digging in the bedding, which is a potentially competing behavior. The room was illuminated at $\sim 40$ lux. A front-mounted closed-circuit TV camera (Security Cameras Direct) was placed at $\sim 1 \mathrm{~m}$ from the cages to record the sessions. Sessions were videotaped for $20 \mathrm{~min}$. The first $10 \mathrm{~min}$ of habituation was not scored. Cumulative time spent grooming all the body regions during the second $10 \mathrm{~min}$ of the test session and the total number of grooming episodes were measured.

Olfactory test. One day before the olfactory test, an unfamiliar food high in carbohydrates (Coco Pops, Kellogg's) was placed overnight in the home cages of the subject mice. Observations of food intake were made to ensure that the novel food was palatable to the mice. On the test day, each mouse was placed in a large cage $(42 \times 26 \times 18 \mathrm{~cm})$ containing $3-\mathrm{cm}$ deep paper-chip bedding and allowed to explore for $5 \mathrm{~min}$. Then, the animal was removed from the cage and one Coco Pop was buried in the cage bedding. The animal was returned to the cage and given $15 \mathrm{~min}$ to locate the buried food. Measures were taken of the time to find the food and whether it was consumed (Moy et al., 2004).

Sociability and preference for social-novelty test. The test mouse was first placed in the middle compartment and allowed to explore the threechambered apparatus for $10 \mathrm{~min}$ (habituation) as previously described (Sala et al., 2011). Then an unfamiliar adult DBA/2J male mouse was placed in one side compartment. On the opposite side was an empty wire cage. For the social-novelty test, performed in the same apparatus without any cleaning, and immediately after the sociability test, one side compartment contained the familiar mouse (from the previous sociability phase), while an unfamiliar mouse was on the other side. The new unfamiliar mouse was placed in the wire cage that had been empty during the prior 10 min session. Familiar and unfamiliar animals from different home cages had never been in physical contact with the subject mice or with each other. For both tests, the time spent in each chamber and the number of entries into each chamber were recorded for $10 \mathrm{~min}$. Data were expressed as the difference score [time spent exploring the compartment containing the familiar mouse minus time spent in the empty compartment (for sociability test), or time spent exploring the compartment containing the strange animal minus time spent exploring the compartment containing the familiar mouse (for social-novelty test)]. An operator blind to genotype manually recorded the time spent in each chamber. We also evaluated the sociability index (SI) and social-novelty preference index (SNI) as follows: $\mathrm{SI}=$ (time exploring novel mouse $1-$ time exploring novel object)/(time exploring novel mouse $1+$ time exploring novel object); SNI $=$ (time exploring novel mouse $2-$ time exploring familiar mouse)/(time exploring novel mouse $2+$ time exploring familiar mouse).

Aggression test. The tested male mouse was placed in the neutral cage (width $41 \mathrm{~cm}$, length $41 \mathrm{~cm}$, height $32 \mathrm{~cm}$ ) never visited before and followed $10 \mathrm{~min}$ later by the opponent DBA/2J male mouse of similar size selected on the basis of its very low aggression scores as described previously (Tordjman et al., 2003). The test lasted $15 \mathrm{~min}$, during which the number of attacks were counted by an experimenter blind to genotype. Attack latency (the time elapsing between the first sniffing until the first attack) was also monitored.

Novel-object recognition test. The novel-object recognition test was performed over a $2 \mathrm{~d}$ period in an open plastic arena $(60 \times 50 \times 30 \mathrm{~cm})$, as previously described (Pan and Xia, 2008). Animals were habituated to the test arena for $10 \mathrm{~min}$ on the first day. After $1 \mathrm{~d}$ habituation, mice were subjected to familiarization (T1) and novel-object recognition (T2). During the initial familiarization stage, two identical objects were placed in the center of the arena equidistant from the walls and from each other. Each mouse was placed in the center of the arena between the two objects for $\leq 20$ min or until it had completed $30 \mathrm{~s}$ of cumulative object exploration. Object recognition was scored when the animal was within $0.5 \mathrm{~cm}$ of an object with its nose toward the object. Exploration was not scored if a mouse reared above the object with its nose in the air or climbed on an object. Mice were returned to the home cage after familiarization and then tested again after different delays (from $5 \mathrm{~min}$ to $24 \mathrm{~h}$ later). A novel object (never seen before) took the place of one of the two familiars. Scoring of object recognition was performed in the same manner as during the familiarization phase. From mouse to mouse the role (familiar or new object) as well as the relative position of the two objects were counterbalanced and randomly permuted. The objects for mice to discriminate consisted of white plastic cylinders and colored plastic Lego stacks of different shapes. The arena was cleaned with $70 \%$ ethanol after each trial. An experimenter blind to the genotype group manually recorded the exploration times to the objects for each animal. Total time spent exploring the two objects during T1 and T2 was also calculated.

Conditioned taste aversion. Mice were individually housed during the conditioned taste-aversion test. After mice were adapted to a restricted drinking schedule ( $20 \mathrm{~min} / \mathrm{d}$ for $4 \mathrm{~d}$ ), they were exposed to a saccharin solution $(0.1 \%)$ followed $1 \mathrm{~h}$ later by a malaise-inducing injection of $\mathrm{LiCl}$ ( 0.15 M, $2 \%$ body weight, i.p.; Bruno et al., 2007). Beginning $48 \mathrm{~h}$ after conditioning, mice could freely choose to drink either saccharin solution or tap water during three daily choice tests. The amount of saccharin intake expressed as the percentage of total fluid consumed [(saccharin/ saccharin + water $) \times 100]$ was taken as an aversion index. An experimenter blind to the genotype group recorded the amount of liquid intake.

Passive avoidance. The apparatus consisted of two compartments, one light and one dark, connected via a sliding door. In the acquisition trial, each mouse was placed in the light compartment and allowed to enter the dark compartment as previously described (Braida et al., 2004). The time (in seconds) taken to do so was recorded. Once the mouse was in the dark compartment, the sliding door was closed and an unavoidable electric shock ( $1 \mathrm{~mA}$ for $5 \mathrm{~s}$ ) was delivered via the paws. The animal was then placed back in the home cage until the retention trial. The retention trial was performed $30 \mathrm{~min}$ after the acquisition trial, by positioning the mouse in the light compartment and recording the time taken to enter the dark compartment (retention latency). Increased retention latency indicates that the animal has learned the association between the shock and the dark compartment. During the retention trial, a cutoff time of $150 \mathrm{~s}$ was used. An experimenter blind to the genotype group recorded the latency time.

Fear conditioning. Fear conditioning occurred in a fear apparatus $(26 \times 26 \times 27 \mathrm{~cm})$ put in a ventilated and sound-attenuated chamber connected to a PC (Panlab). The floor consisted of 19 steel rods through which a scrambled shock could be delivered. The sidewalls were made of black stainless steel and the door was made of Plexiglas. Before the start 
of the test, mice were handled every day for a week. Then, animals were transported from the colony room to the fear-conditioning room where training and testing took place. There, animals were habituated to the environment for $30 \mathrm{~min}$. After each testing session, animals were returned to their home cages. All mice underwent $3 \mathrm{~d}$ of behavioral testing. The day of conditioning (Day 1), animals individually received, after 2 min of exploration, five trials consisting of the presentation of a sound $[85 \mathrm{~dB}$ tone conditioned stimulus (CS) for $28 \mathrm{~s}$ ] and shock [unconditioned stimulus (US): 0.25 intensity] for $2 \mathrm{~s}$ followed by an intertrial period of $30 \mathrm{~s}$. Acetic acid (5\%) was used for cleaning in between training sessions. To assess memory consolidation, $24 \mathrm{~h}$ after training (Day 2) mice were re-exposed to the training chamber for $120 \mathrm{~s}$ without activation of the CS or US (context test). Twenty-four hours later (Day 3), the floor and walls were changed for a new context configuration, using a transparent cylinder, white walls, and a smooth floor, and odor (ethanol 4\%). Mice were re-exposed to this modified context chamber. After 2 min of habituation, the sound was given for $3 \mathrm{~min}$. Data acquisition, control of stimuli (white noise and foot shock), and data analysis were performed automatically using Packwin software (Panlab). The percentage of freezing during different sessions was evaluated and defined as percentage of time the animal was immobile except for breathing.

T maze. Mice were deprived of food until they had reached $85-90 \%$ of their ad libitum-feeding body weight. They were habituated to a black wooden T maze for $5 \mathrm{~d}$ as previously described (Sala et al., 2011). In the acquisition phase, one arm was designated as the reinforcer (Coco Pops, Kellogg's) for each of 10 daily trials. Each mouse was placed at the start of the maze and given a free choice to enter either arm. The number of days to reach the criterion ( $80 \%$ of correct choices for $3 \mathrm{~d}$ ) was recorded.

Morris water maze. The Morris water-maze test (Morris, 1984), adapted for mice, was used to examine the changes in learning and memory abilities. A circular water maze $(120 \mathrm{~cm}$ in diameter $\times 50 \mathrm{~cm}$ in height) was used. A circular hidden platform with a diameter of $10 \mathrm{~cm}$ was inside the maze and the surface was $0.5 \mathrm{~cm}$ below the surface of the water. Floating plastic particles were placed on the surface of the water to hide the platform (zharv;71Zhang et al., 2013). The temperature of the water was $25.0 \pm 0.5^{\circ} \mathrm{C}$. For the habituation trial, mice were placed in a random area inside the maze for $60 \mathrm{~s}$. For the acquisition trial, mice performed four trials per day (with $60 \mathrm{~s}$ intertrial interval) for 4 consecutive days in which each mouse was released to the pool from different starting points and trained to a constant platform position. Twenty-four hours after the last trial a probe test was performed during which the platform was removed. An experimenter blind to genotype evaluated the time spent in the target area. After each trial, mice were placed on a paper towel for additional drying and then put back into their home cages.

Radial maze. Working memory was studied using a computerized wooden eight-arm radial maze (Braida et al., 2004). Animal behavior was monitored by a video camera (Model CCD, Securit Alarmitalia) whose signals were digitized and interfaced by a PF6PLUSPAL apparatus $(512 \times$ 512 pixels; Imaging Technology), and sent to a video monitor (Trinitron $\mathrm{KX}-14 \mathrm{CP} 1$, Sony). Image analysis and pattern recognition were done by a Delta System computer (Addonics) using software provided by Biomedica Mangoni. During each daily session, working memory was scored on the basis of the total number of errors (which corresponded to a re-entry into the arm just visited). Starting 2 weeks before the experiment, the body weights of the WT and ILIRAPL1 mice were reduced by $10 \%$ by means of a restricted feeding schedule of standard chow (Harlan). After $3 \mathrm{~d}$ of free exploration, the animals were trained to complete the maze. Training continued, at the rate of one trial per day, until the mice reached the criterion of entering seven different arms in their first eight choices on 5 successive days, for a maximum of 3 weeks. The mean number of days taken to reach the criterion and the percentage of animals reaching the criterion were calculated.

\section{Behavioral data analysis}

Data, expressed as means \pm SEM or percentage, were statistically analyzed and displayed by Prism 6 software (GraphPad). Student's $t$ test was used to analyze the means. Frequencies were analyzed by Fisher's exact probability test. Two-way ANOVA for multiple comparisons, followed by Bonferroni's test was used. The learning acquisition in the Morris water maze and radial maze was calculated as AUC. The accepted level of significance was $p \leq 0.05$ ).

\section{Golgi staining}

Three-month-old male mice were perfused transcardially with $0.9 \%$ $\mathrm{NaCl}$ in distilled water. The brain was taken and immersed in Golgi-Cox solution $\left(1 \% \mathrm{~K}_{2} \mathrm{Cr}_{2} \mathrm{O}_{7}, 1 \% \mathrm{HgCl}_{2}, 1 \% \mathrm{~K}_{2} \mathrm{CrO}_{4}\right.$ all Sigma-Aldrich; Glaser and Van der Loos, 1981) for 2-6 d in the dark, at room temperature. Golgi-Cox solution should be prepared $\geq 5 \mathrm{~d}$ before the impregnation, stored in the dark, and filtered before use. After the period of impregnation, the brain was washed three times with distilled water, immersed in a $30 \%$ sucrose solution, and stored at $4^{\circ} \mathrm{C}$, in the dark, for $\geq 1$ week.

The brain was cut with a vibratome setting frequency at 5.0, speed at 3.0, and slice thickness at $80-100 \mu \mathrm{m}$; during the operation, the sample was kept wet with a $6 \%$ sucrose solution. Slices were put on gelatinized slides ( $2 \%$ gelatin, $1 \% \mathrm{KCr}\left(\mathrm{SO}_{4}\right) 12 \mathrm{H}_{2} \mathrm{O}$; all Sigma-Aldrich).

Slices was stained in the dark. First, slides were washed two times with distilled water for $5 \mathrm{~min}$, then put $30 \mathrm{~min}$ in ammonium hydroxide (Sigma-Aldrich). After more distilled water washes, slides were put in Kodak solution (Sigma-Aldrich) for $30 \mathrm{~min}$. Slides were washed two times in distilled water, and then $1 \mathrm{~min}$ in each crescent percentage of ethanol (Fluka; 50, 70, and 95\%) and two times for $5 \mathrm{~min}$ in $100 \%$ ethanol. Finally, slides were immersed for $15 \mathrm{~min}$ in solution X [one-third chloroform (Sigma-Aldrich), one-third xylene (Carlo Erba), one-third ethanol] and then $15 \mathrm{~min}$ in xylene. Slides were mounted on coverslips with Entellam (Electron Microscopy Sciences). Images were taken with a $20 \times$ objective in a white field. Neurons were analyzed with Neuron Studio software to perform a Sholl analysis of branching points.

\section{Preparation and neuronal differentiation of iPS cells}

iPS cells were derived from reprogramming of fibroblasts obtained from a skin biopsy from a healthy donor and Patient $\mathrm{J}$, who carried a deletion of exon 6 ( $\Delta$ exon 6$)$ in the IL1RAPL1 gene (Ramos-Brossier et al., 2015).

Fibroblasts were collected according to a clinical protocol approved by the local bioethical committees of different medical centers. Participating individuals were informed of the objectives of the study and signed an informed consent before inclusion in the study.

Detailed procedures used for the generation, maintenance, and characterization of iPS cells were previously described by Verpelli et al. (2013) and Carlessi et al. (2014). Immunofluorescence and reverse transcriptase PCR (RT-PCR) experiments were performed to detect pluripotency markers (Oct3/4, Lin28, Nanog, and Sox2).

Briefly, iPS cell reprogramming was performed with the classical Yamanaka factors (Takahashi and Yamanaka, 2006). Then iPS cells were differentiated to neural precursors (hNPs) via the embryoid bodies method (Verpelli et al., 2013; Carlessi et al., 2014).

Characterization of the control and Patient $J$ cells was performed on two lines of differentiated hNPs (obtained from different clones) at the same passages. The characterization consists of immunofluorescence experiments to detect neural precursor markers (Sox2 and Nestin) and RT-PCR experiments to confirm the presence of the $\Delta$ exon 6 mutation.

Neural precursors were infected with EGFP-carrying lentivirus with efficiency close to $100 \%$ and differentiated to neuronal cells cocultured with cortical primary culture from rat embryos at DIV 7-11 (Verpelli et al., 2013). Thirty thousand hNPs were plated onto the cortical neurons and the medium was changed every $7 \mathrm{~d}$. The differentiation takes $\geq 30 \mathrm{~d}$ and we obtained a culture enriched with glutamatergic neurons. iPSderived neurons were electrophysiologically characterized by voltagegated currents and action potential recordings.

\section{Immunocytochemistry}

Cells were fixed in $4 \%$ PFA plus $4 \%$ sucrose at room temperature for $20 \mathrm{~min}$, or $100 \%$ methanol at $-20^{\circ}$ for $10 \mathrm{~min}$. Primary $(1: 100-1: 800)$ and secondary (1:200) antibodies were applied in GDB buffer $(30 \mathrm{~mm}$ phosphate buffer, $\mathrm{pH} 7.4,0.2 \%$ gelatin, $0.5 \%$ Triton $\mathrm{X}-100,0.8 \mathrm{M} \mathrm{NaCl}$; all Sigma-Aldrich) or in PBS (136.8 mM NaCl, $2.68 \mathrm{~mm} \mathrm{KCl,} 10.1 \mathrm{~mm}$ $\mathrm{Na}_{2} \mathrm{HPO}_{4}$, and $1.76 \mathrm{~mm} \mathrm{KH} 2 \mathrm{PO}_{4}$, pH 7.4; all Sigma-Aldrich) containing $3 \%$ BSA and $0.2 \%$ Tween 20 .

Primary antibodies were applied for $1-3 \mathrm{~h}$ at room temperature. Secondary antibodies conjugated with fluorophores (Jackson ImmunoResearch) 
were also diluted in GDB buffer and applied for $1 \mathrm{~h}$. After each antibody incubation, three washes (10 min each) took place with "high-salt buffer" (20 $\mathrm{mM} \mathrm{Na}_{2} \mathrm{HPO}_{4} / \mathrm{NaH}_{2} \mathrm{PO}_{4}$ and $0.5 \mathrm{M} \mathrm{NaCl}$, $\mathrm{pH}$ 7.4; all Sigma-Aldrich) and, before mounting, a final wash (for $10 \mathrm{~min}$ ) was performed with PBS. Before mounting, coverslips were briefly passed through doubledistilled $\mathrm{H}_{2} \mathrm{O}$ to dilute salts. Four',6-diamidino-2-phenylindole (DAPI) staining (Life Technologies) was performed for 2 min (DAPI diluted in PBS to a final concentration of $0.5 \mu \mathrm{g} / \mathrm{ml}$ ) and took place during the washing steps before mounting the coverslips with mounting medium (Vectashield).

\section{Image acquisition and processing}

Confocal images were obtained using a Zeiss 510 confocal microscope (Carl Zeiss; a gift from Fondazione Monzino) or a Leica DMI6000 spinning disk microscope (PerkinElmer; a gift from Fondazione Monzino) with Zeiss $63 \times, 40 \times$, or $20 \times$ objectives at a resolution of $1024 \times 1024$ pixels. Images represent maximum intensity projections of five individual images taken at depth intervals of $\sim 0.5 \mu \mathrm{m}$.

Quantification of synaptic protein staining was performed using MetaMorph (Molecular Devices), and with ImageJ software and the NeuronJ plugin (Meijering et al., 2004). Labeled, transfected cells were chosen randomly for quantification from six coverslips from three independent experiments for each condition. Image analysis was performed under blind conditions.

Quantification of protein surface staining was performed using MetaMorph (Molecular Devices) and ImageJ software. The ratio of integrated intensity of surface rabbit anti-HA signal per total mouse anti-HA signal was measured for each neuron. Then we calculated the mean and SEM for the neurons transfected with the same construct.

The morphologic analysis was performed on the GFP signal channel image. Sholl analysis was performed using NeuronStudio (Computational Neurobiology and Imaging Center, Mount Sinai School of Medicine, New York, NY) to measure the number of branching points to evaluate the dendritic arborization complexity in adult neurons (DIV 14-15) and iPS cell-derived neurons.

Young neurons (at DIV 4), adult neurons (DIV 15), and iPS cellderived neurons were analyzed manually to count the number of primary and secondary dendrites, together with the total and average length of counted dendrites using MetaMorph software.

\section{Data analysis and figure display}

Data were analyzed for statistical significance and displayed by Prism 5 software (GraphPad). If there were only two groups whose means were compared, a Student's $t$ test was performed to assess statistical significance. The accepted level of significance was $p \leq 0.05$. To compare $>2$ groups, one-factorial ANOVA was used and if group means differed in a significant manner ( $p \leq 0.05$ ), post hoc Dunnet's (groups compared with the control), Bonferroni's, and Tukey's (all groups compared) tests were calculated to assess statistical significance. The accepted level of significance for the post hoc test was $p \leq 0.05$. In graph, data are presented as mean \pm SEM.

\section{Electrophysiology}

Total voltage-gated currents and action potentials were recorded from differentiated neurons at room temperature $\left(\sim 25^{\circ} \mathrm{C}\right)$ using an Axopatch200B amplifier and pClamp 10.5 software (Molecular Devices) in the whole-cell configuration of the patch-clamp technique. Signals were filtered at $10 \mathrm{kHz}$ and sampled at $200 \mathrm{kHz}$ for voltage-clamp recordings or $20 \mathrm{kHz}$ for current-clamp recordings. Differentiated neurons were identified by GFP fluorescence. To allow intracellular dialysis with the pipette solution, recordings usually started $5 \mathrm{~min}$ after the rupture of the membrane patch. External bath solution contained the following (in $\mathrm{mm}$ ): $129 \mathrm{NaCl}, 1.25 \mathrm{NaH}_{2} \mathrm{PO}_{4}, 35$ glucose, $1.8 \mathrm{MgSO}_{4}, 1.6 \mathrm{CaCl}_{2}, 3 \mathrm{KCl}$, and 10 HEPES, pH 7.4, with $\mathrm{NaOH}$. The internal pipette solution contained the following (mM): $120 \mathrm{~K}$-gluconate, $15 \mathrm{KCl}, 2 \mathrm{MgCl}_{2}, 0.2$ EGTA, 10 HEPES, $20 \mathrm{~mm}$ phosphocreatine-tris, $2 \mathrm{~mm}$ ATP-Na $2,0.2 \mathrm{~mm}$ GTP$\mathrm{Na}_{2}$, and $0.1 \mathrm{~mm}$ leupeptin, pH 7.2, with $\mathrm{KOH}$. Pipette resistance was between 3 and $4 \mathrm{M} \Omega$. Cell capacitance and series resistance errors were carefully compensated $(\sim 85 \%)$ throughout the experiment. The remaining linear capacity and leakage currents were eliminated on-line using a $\mathrm{P} / 4$ subtraction paradigm. Total voltage-gated currents were elicited by applying 66-ms-long depolarizing voltage steps from -70 to $+50 \mathrm{mV}$, from a holding potential of $-70 \mathrm{mV}$. Action potentials were evoked by the injection of 2.5-s-long depolarizing current pulses of increasing amplitude from a resting potential clamped at $-70 \mathrm{mV}$.

\section{$R N A$ isolation and real-time quantitative PCR}

RNA was isolated from neural precursor cells using Trizol reagent (Invitrogen), according to the manufacturer's instructions. cDNA was synthetized from $1 \mu \mathrm{g}$ of RNA (Maxima reverse transcriptase, Thermo Fisher Scientific). The relative abundance of IL1RAPL1 mRNA was obtained with real-time quantitative PCR using SYBR Green I and LightCycler (Roche Diagnostics). To determine the presence of exon 6 using Exon5F and Exon7R primers, PCR products were resolved on 1.5\% agarose gel. All primers were designed to span an exon-exon junction to avoid the PCR amplification from RNA contaminating genomic DNA. The primers used were as follows: Exon8F_acgtcgacacgccagcgttc, Exon9R_gcaccaagg cctccagcaagtt, Exon5F_acaaaaacatggaggccaag, Exon7R_aggactgacatctccgctg.

$G A P D H$ and $E E F 1 G$ were both used as reference genes. mRNA relative abundance was calculated using the 2- $\Delta \Delta$ CT method (Livak and Schmittgen, 2001).

\section{cDNA constructs}

HA-tagged human IL1RAPL1 described previously (Pavlowsky et al., 2010a) was modified using the QuikChange II XL Site-Directed Mutagenesis Kit (Agilent Technologies) to generate $\Delta$ ex6, C31R, I643V, and $\Delta \operatorname{Ig} 123$ constructs (Ramos-Brossier et al., 2015). Myc-tagged PTP $\delta$ and PTP $\delta E C T O$, IL1RAPL1 $\Delta$ C, IL1RAPL1 $\Delta$ N, IL1RAPL1 $\Delta 8$, IL1RAPL2, and GFP-PSD-95 have been described previously (Valnegri et al., 2011b). For the IL1RAPL1 amino acid 1-558 construct, we inserted a stop codon at amino acid 558

Human PTP $\delta$ full length was a gift from E. Kim (Kwon et al., 2010). Rat PTP $\delta$ without miniexons A and B was a gift from M. Mishina (Yoshida et al., 2011). shRNA plasmid against rat PTP $\delta$ was a gift from A.M. Craig (Takahashi et al., 2011). Human TSPAN7 was a gift from M. Passafaro (Bassani et al., 2012). All these transmembrane protein cDNA were inserted in a GW1-CMV vector. The signal peptide of IL1RAPL1 (amino acids 1-25) and PTP $\delta$ was switched with the signal peptide of GluR2 (AMPA receptor subunit), a cleavable signal peptide, to ensure membrane localization. Downstream, an HA tag was inserted.

For in utero electroporation experiments, HA-IL1RAPL1 FL and HA-IL1RAPL1 C31R were subcloned into pCAGGS-IRES-EGFP plasmid, a gift from L. Cancedda (dal Maschio et al., 2012). As control, pEGFP vector was also used.

\section{Lentivirus production}

Genetically modified lentiviruses were produced as previously described (Naldini et al., 1996; Lois et al., 2002) and the production was performed with second-generation and third-generation lentiviral transfer vectors.

\section{Antibodies}

The following primary antibodies were used: goat anti-IL1RAPL1 (R\&D Systems), rabbit anti-IL1RAPL1 (Proteintech), mouse anti-GFP (Roche), rabbit anti-HA-tag (Santa Cruz Biotechnology), mouse anti-HA-tag (Roche), mouse anti-PSD-95 (Neuromab), mouse anti- $\beta$-Actin (SigmaAldrich), mouse anti-Bassoon (Enzo Life Science), mouse anti-Oct3/4 (Santa Cruz Biotechnology), rabbit anti-Sox2 (Proteintech), mouse antiNestin (Millipore). All HRP-conjugated and fluorophore-conjugated secondary antibodies were purchased from Jackson ImmunoResearch Labs.

\section{Cell culture and transfection of primary rat hippocampal neurons and COS-7 cells}

Low-density rat hippocampal neuronal cultures were prepared from embryonic day (E)18-19 hippocampi as previously described with minor modifications (Romorini et al., 2004; Verpelli et al., 2010) and were grown in 12-well Petri dishes (Primo). Neurons were transfected using Lipofectamine 2000 on DIV 11 and experiments were performed at DIV 14-18. Alternatively, neuronal primary cultures were transfected at DIV 1 with the calcium chloride method as described previously (Verpelli et 
al., 2010) and experiments were performed at DIV 4. The COS-7 cells were transfected using jetPEI (Polyplus); cells were used for the experiments $48 \mathrm{~h}$ after transfection.

\section{In utero electroporation, slice histology, and immunostaining}

The in utero electroporation procedure took place as previously described (dal Maschio et al., 2012) with minor modifications. Briefly, E15.5 timed-pregnant cd1 mice were anesthetized and the uterine horns were exposed by laparotomy. The DNA ( $1-2 \mu \mathrm{g} / \mu \mathrm{l}$ in water) together with the dye Fast Green $(0.3 \mathrm{mg} / \mathrm{ml}$; Sigma-Aldrich) was injected $(5-6 \mu \mathrm{l}$ using a 30 gauge needle) through the uterine wall into one of the lateral ventricles of each embryo. After soaking the uterine horn with a PBS solution, the embryo's head was carefully held between tweezer-type circular electrodes and the electrical pulses were delivered. The uterine horns were returned into the abdominal cavity after electroporation, and embryos were allowed to continue their normal development. Ninety days after birth, mice were fixed by transcardial perfusion of $4 \%$ paraformaldehyde (PFA) in PBS. Brains were sectioned coronally at 80-100 $\mu \mathrm{m}$ thickness with a vibratome. Free-floating slices were permeabilized and blocked with PBS containing $0.4 \%$ Triton X-100, 10\% normal goat serum, and $3 \%$ bovine serum albumin (BSA; all Sigma-Aldrich). Primary and secondary antibodies were incubated in the same blocking solution. Slices were counterstained with DAPI (Sigma-Aldrich) and examined with confocal microscopy.

\section{Neuron surface staining}

At DIV 14-15, live hippocampal neurons were labeled for $10 \mathrm{~min}$ at $37^{\circ} \mathrm{C}$ with anti-HA-tag rabbit antibody $(10 \mu \mathrm{g} / \mathrm{ml})$. After washing, neurons were fixed with PFA $4 \%$ plus $4 \%$ sucrose and incubated with anti-HA-tag mouse antibody in GDB (30 mm phosphate buffer, $\mathrm{pH} 7.4,0.2 \%$ gelatin, $0.5 \%$ Triton X-100, $0.8 \mathrm{M} \mathrm{NaCl}$; all Sigma-Aldrich) for $3 \mathrm{~h}$ at room temperature. Cells were washed in $20 \mathrm{~mm}$ phosphate buffer containing $0.5 \mathrm{M} \mathrm{NaCl}$ and incubated with FITC-conjugated and $\mathrm{Cy} 3$-conjugated secondary antibodies.

\section{Coimmunoprecipitation and immunoblotting}

For the coimmunoprecipitation experiment, anti-HA antibodies were conjugated to protein A Sepharose beads (GE Healthcare), added to cell lysate prepared using RIPA buffer, and incubated overnight at $4^{\circ} \mathrm{C}$. The beads were washed three times with RIPA buffer, and elution was performed in sample buffer for SDS-PAGE $\left(5 \mathrm{~min}\right.$ at $\left.100^{\circ} \mathrm{C}\right)$ and loaded to $10 \%$ SDS-PAGE for immunoblotting analysis.

For immunoblotting, cells were lysed and an equal amount of protein was submitted to SDS-PAGE and transferred to a nitrocellulose membrane. Membranes were incubated overnight with primary antibodies and, after incubation, with HRP-conjugated secondary antibodies. Super Signal West Femto and ECL substrate (Pierce) were used for revelation. Acquisition was performed with LAS-4000 (General Electric) and quantification of band intensity was done with ImageJ software.

\section{Results}

\section{Altered cognitive functions in the KO mice}

It was previously demonstrated that Il1 rapl1-KO mice have reduced anxiety-like behavior and some memory impairments (Houbaert et al., 2013; Yasumura et al., 2014). We further analyzed our Il1 rapl1-KO mice (Pavlowsky et al., 2010a; Houbaert et al., 2013) with different behavioral assays to fully characterize their phenotype.

We first tested Il1rapl1-KO male mice and their littermates for their anxiety-like profile using elevated plus maze, marbleburying, and novelty suppressed feeding tests. In the elevated plus maze, we found that Il1 rapl1-KO mice made more entries $\left(t_{(18)}=\right.$ $3.92, p=0.01)$ and spent more time $\left(t_{(18)}=10.60, p=0.0004\right)$ in the open arms compared with their WT littermates (Fig. $1 A$, left and center), but the total number of entries into the arms of the maze was comparable $\left(t_{(18)}=0.54, p=0.61\right)$ in the two genotypes (Fig. 1A, right). In the marble-burying test, we found a significant decrease $\left(t_{(18)}=3.03, p=0.008\right)$ in the number of buried marbles in Il1rapl1-KO mice compared with WT littermates. We also found in Il1 rapl1-KO mice, compared with WT littermates, an increased latency to the first burial $\left(t_{(18)}=2.77\right.$, $p=0.014$; Fig. 1B). Finally, in the novelty suppressed feeding test, Il1 rapl1-KO mice exhibited a significant decrease of latency to the first food bite $\left(t_{(18)}=2.43, p=0.029\right)$ and to feed in the center of the arena $\left(t_{(18)}=3.09, p=0.007\right)$, compared with WT littermates. No difference was found in the food intake evaluated 5 min after the test between the two genotypes, indicating a similar motivation to feed (Fig. $1 C$ ). Altogether, these results indicate that complete lack of Il1rapl1 expression affects basal anxiety, resulting in a low-anxiety phenotype. Il1 rapl1-KO mice were hyperactive (Fig. 1D), having higher levels of horizontal counts evaluated in the activity cage than their WT littermates (genotype as between-subjects factor, $F_{(1,72)}=53.8, p<0.0001$; time as within-subjects factor, $F_{(3,72)}=48.12, p<0.0001$; genotype $\times$ time interaction, $F_{(3,72)}=2.38, p<0.05$; two-way ANOVA) and vertical counts (genotype as between-subjects factor $\left(F_{(1,72)}=\right.$ 84.58, $p<0.0001$; time as within-subjects factor, $F_{(3,72)}=22.45$, $p<0.0001$; genotype $\times$ time interaction, $F_{(3,72)}=4.73, p<$ 0.007; two-way ANOVA). Bonferroni's post hoc test revealed significant differences at almost all tested intervals. The mean total amount of horizontal and vertical counts, evaluated within $4 \mathrm{~h}$, was higher in mutant mice compared with WT mice $\left(t_{(18)}=3.30\right.$, $\left.p<0.01 ; t_{(18)}=3.44, p<0.007\right)$.

Mice of both genotypes built normal nests (Fig. 1E; genotype as between-subjects factor, $F_{(1,72)}=3.63, p=0.46$; time as within-subjects factor, $F_{(3,72)}=3.64, p=0.02$; genotype $\times$ time interaction, $F_{(3,72)}=0.73, p=0.5$; two-way ANOVA). Bonferroni's post hoc test revealed a slight increase of score in both genotypes from the first to the fourth day, suggesting a progressive learning for both groups.

We then tested the mice for repetitive behavior. We observed in the Il1 rapl1-KO mice, compared with the WT mice, significantly more self-grooming activity in terms of time spent grooming $\left(t_{(18)}=3.10, p=0.02\right)$ and the number of grooming episodes $\left(t_{(18)}=4.21, p=0.008\right.$; Fig. $\left.1 F\right)$. In the Olfactory test, the mutant and the WT mice were similarly able to locate the buried food (Fig. $1 G ; t_{(18)}=0.34, p=0.74$ ).

When tested for sociability (Fig. $1 H$ ), Il1 rapl1-KO mice were normal, spending more time to investigating the stranger mouse compared with the compartment with the empty cage (difference score: $t_{(18)}=0.64, p=0.52$; social index: $\left.t_{(18)}=0.06, p=0.94\right)$. Ill rapl1-KO mice were also normal in the social novelty test, remaining close to the novel stranger mouse compared with the familiar mouse (difference score: $t_{(18)}=0.27, p=0.78$; social novelty index: $t_{(18)}=1.39, p=0.18$; Fig. $\left.1 H\right)$.

However, aggressive behavior (Fig. 1I) was significantly decreased compared with WT mice, as shown by the increased latency to the first attack $\left(t_{(18)}=2.6, p=0.05\right)$ and decreased number of attacks $\left(t_{(18)}=2.57, p=0.04\right)$.

When tested for memory in the novel object recognition test (Fig. 2A), two-way ANOVA revealed differences (genotype as between-subjects factor, $F_{(1,54)}=15.29, p=0.0003$; time as within-subjects factor, $F_{(2,54)}=3.33, p=0.04$; genotype $\times$ time interaction, $\left.F_{(2,54)}=3.82, p=0.03\right)$. Bonferroni's post hoc test showed a decrease in the discrimination index of Ill rapl1-KO mice compared with their WT littermates at a delay of $30 \mathrm{~min}$ and 24 h. Il1 rapl1-KO and WT mice spent similar time exploring the novel and familiar objects, except when $24 \mathrm{~h}$ delay was applied (genotype as between-subjects factor, $F_{(1,72)}=32.2, p=0.0001$; time as within-subjects factor, $F_{(3,72)}=1.62, p=0.66$; genotype $\times$ time interaction, $\left.F_{(3,724)}=13.58, p=0.006\right)$. In this case, 
A Elevated Plus Maze

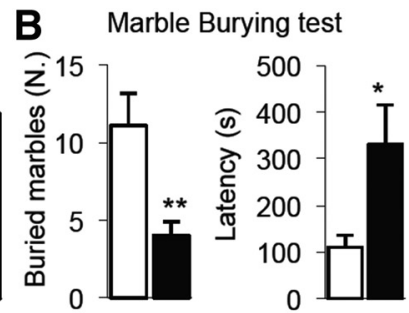

C Novelty suppressed feeding

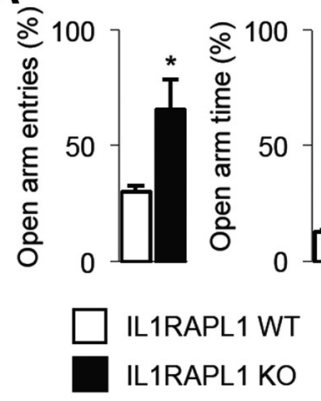

D

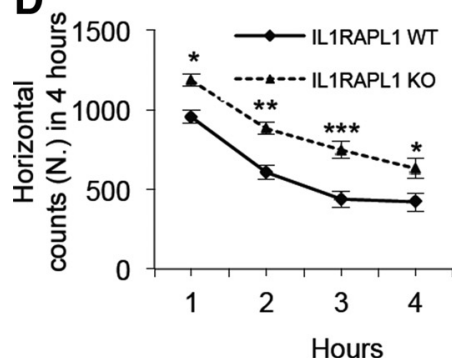

$\mathbf{E}$
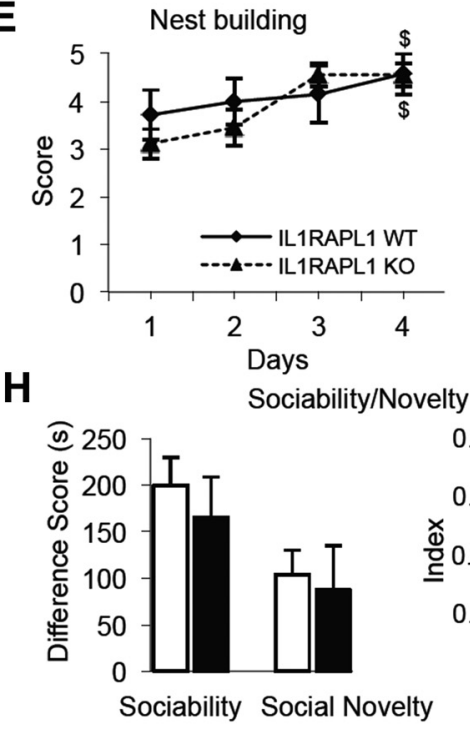

Spontaneous motor activity

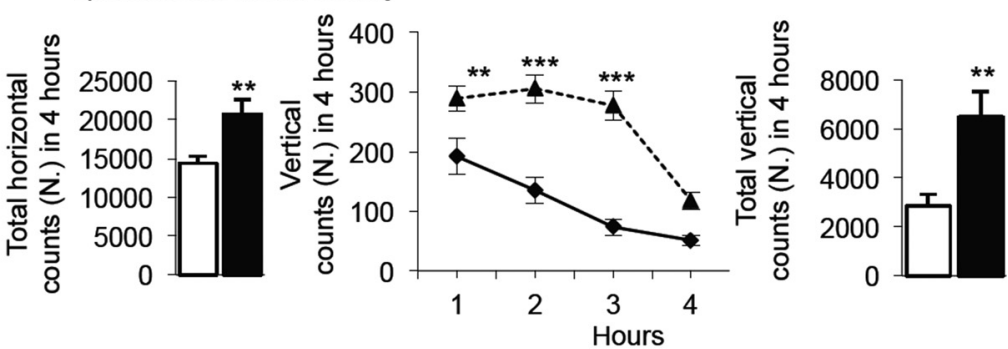

$\mathbf{F}$
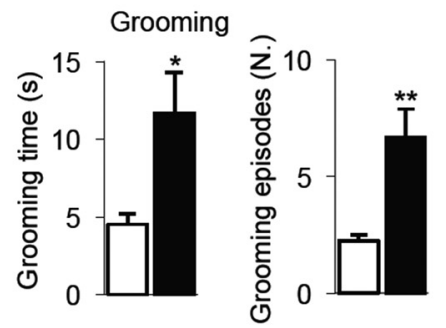

G

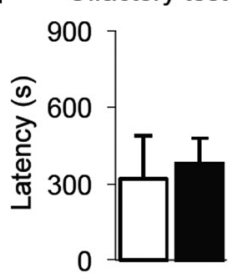

I

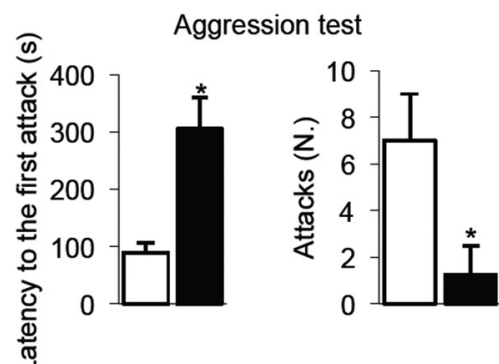

Figure 1. I/1rap/1-K0 mice exhibit abnormal anxiety-like behavior, motor activity, abnormal basal behavior in terms of self-grooming and aggression compared with their littermates (WT). $\boldsymbol{A}$, Open arm entries (left), time in open arms (center), and total entries (right), evaluated in the elevated plus maze, over 5 min. $\boldsymbol{B}$, Number of marbles buried (left) and latency to the first burial (right) evaluated in the marble-burying test over $15 \mathrm{~min}$. C, Latency to feed (left) in $20 \mathrm{~min}$ and total amount of food intake, evaluated over 5 min, during the novelty suppressed feeding test. $\boldsymbol{D}$, Horizontal (upper) and vertical (bottom) counts, evaluated in an automated activity cage, recorded every hour (left) and mean counts over $4 \mathrm{~h}$ (right). $\boldsymbol{E}$, Nest-building behavior in terms of score. $\boldsymbol{F}$, Self-grooming behavior evaluated in terms of time spent to do grooming (left) and total number of grooming episodes (right) over 10 min. $\mathbf{G}$, Mean latency to locate the buried food in the olfactory test over $15 \mathrm{~min}$. $\boldsymbol{H}$, Social behavior in terms of difference score (left) and index (right) in sociability and social novelty task. $\boldsymbol{I}$, Aggressive behavior expressed as total number of attacks against intruder (left) and mean latency to the first attack (right). Data are presented as mean \pm SEM. ${ }^{*} p<0.05,{ }^{* *} p<0.01,{ }^{* * *} p<0.001$ versus corresponding WT; $\$ p<0.05$ versus corresponding Day 1 , same genotype (Student's $t$ test or 2-way ANOVA followed by Bonferroni's test). $n=8-10$ per genotype.

Ill rapl1-KO mice spent more time exploring both objects compared with WT mice.

When tested for conditioned taste aversion (Fig. 2B), Illrapl1-KO mice showed a greater amount of saccharin intake compared with that of WT mice, suggesting a lack of association with visceral malaise induced by $\mathrm{LiCl}\left(t_{(18)}=2.39, p=0.04\right)$. In the passive avoidance task (Fig. $2 C$ ), genotypes did not differ, resulting in similar response latencies $\left(t_{(18)}=0.79, p=0.44\right)$.

To assess memory in Ill rapl1-KO and WT mice, animals were conditioned to five pairs of auditory cues and foot shocks in the conditioning session (training). Twenty-four hours after the conditioning, fear memory was assessed by exposure to the condi- tioning context (context test) followed by, $24 \mathrm{~h}$ later, altered context without and with auditory cue (cued test). There was a significant difference in the percentage of freezing between genotypes $\left(F_{(1,24)}=\right.$ $5.87, p=0.02)$, sessions $\left(F_{(2,24)}=29.15, p<0.0001\right)$, and the interaction between genotype and sessions $\left(F_{(2,24)}=12.96, p=0.0002\right)$. Post hoc analysis revealed that no difference was shown between the two genotypes during training and in the context test while a difference in the percentage of freezing between the two genotypes during cued test was found (Fig. 2D).

We then observed mice in T-maze (Fig. 2E), water-maze (Fig. $2 F$ ), and radial-maze (Fig. $2 G$ ) tasks, which rely on an intact hippocampus-dependent spatial memory. In the T-maze task, 
A

Novel Object Recognition test $\square$ IL1RAPL1 WT
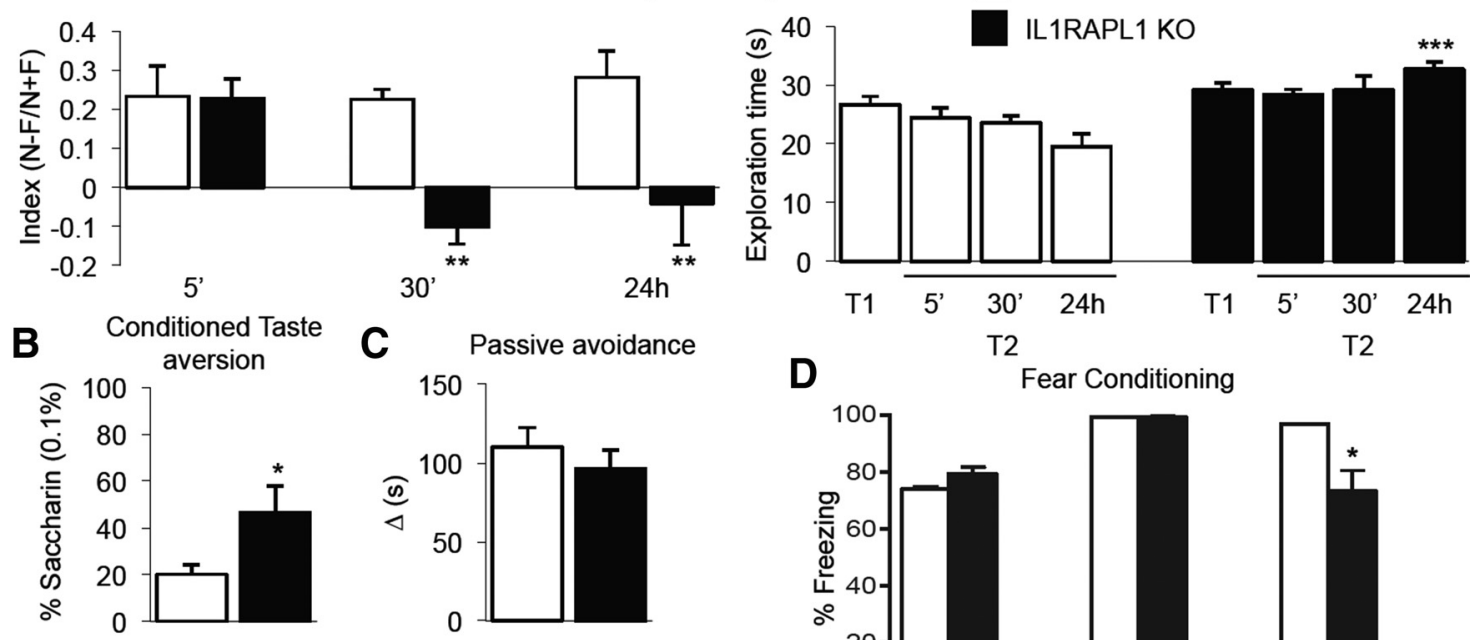

E
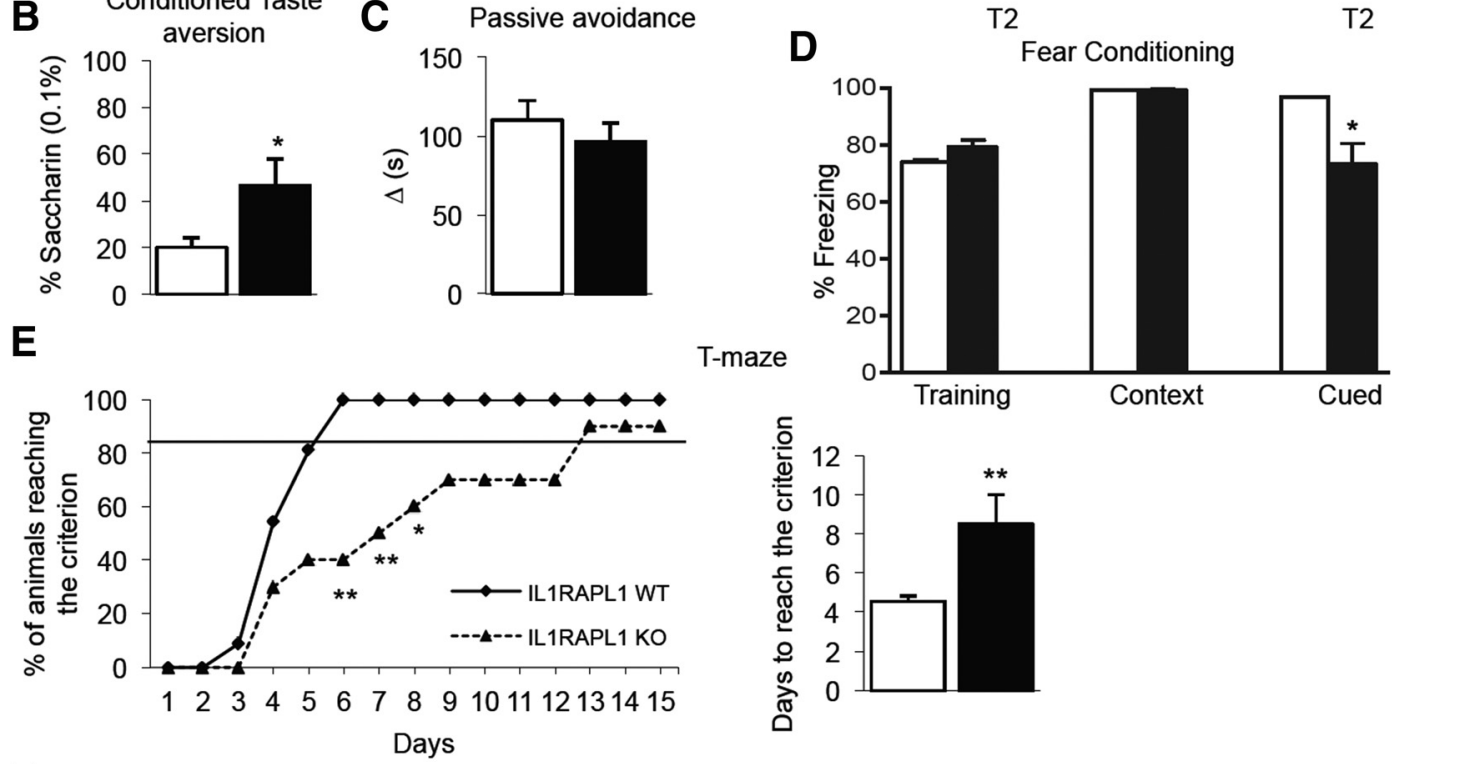

T-maze

F

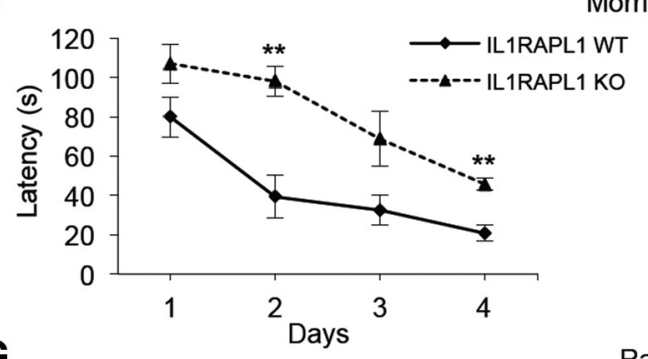

Morris water maze
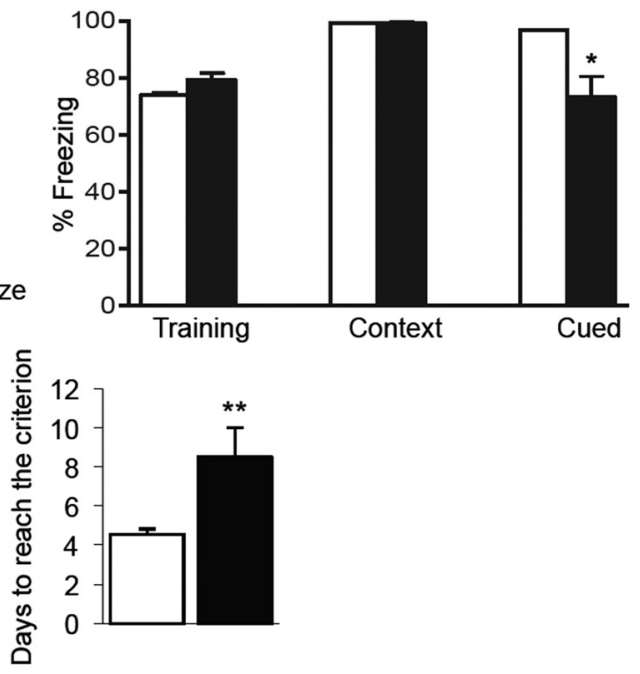

G
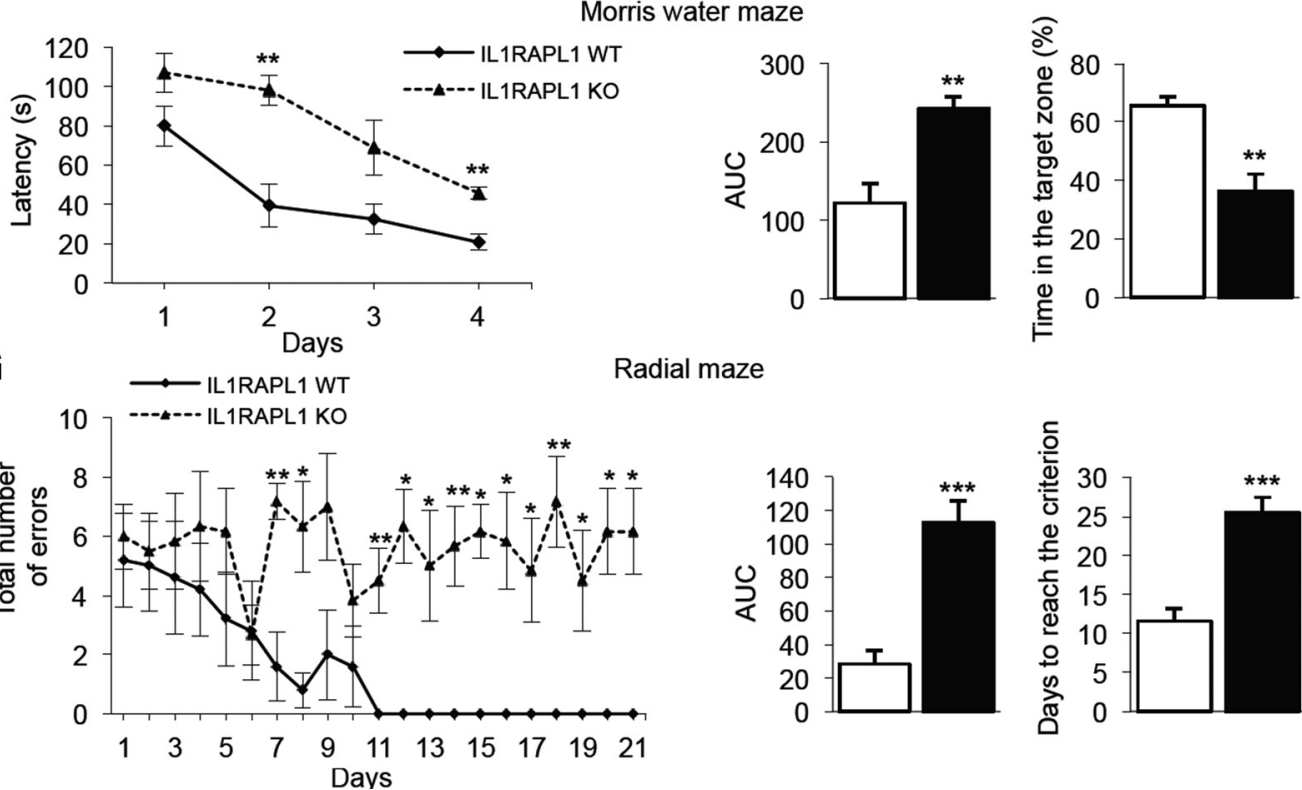

Radial maze

Figure 2. I/1rap/1-K0 mice are impaired in episodic, aversive, fear, and spatial memory. A, Discrimination index (after a delay of $5 \mathrm{~min}, 30 \mathrm{~min}$, and $24 \mathrm{~h}$ ) and corresponding exploration time, during $\mathrm{T} 1$ and T2, in the novel object recognition test. $\boldsymbol{B}$, Saccharin intake in conditioned taste-aversion task. $\boldsymbol{C}$, Mean latency (seconds) to re-enter the dark compartment in the passive avoidance test. $\boldsymbol{D}$, Freezing behavior (\%) was measured in the context and cued fear-conditioning test to assess fear memory. Data are shown as mean \pm SEM of five mice for each group. ${ }^{* * *} p<0.0001$ compared with corresponding WT cued (2-way ANOVA, Bonferroni's test). $\boldsymbol{E}$, Acquisition learning in the T-maze task in terms of number of animals reaching the criterion and time to reach the criterion. $\boldsymbol{F}$, Acquisition learning in the Morris water-maze task in terms of latency to reach the hidden platform (left), corresponding AUC (center), and time spent in the targetzone during probetest (right). G, Acquisition learning in the radial-maze task, in terms of total number of errors (left), corresponding AUC (center), and number of days to reach the criterion (right), compared with WT mice. Data are presented as mean \pm SEM or percentage. ${ }^{*} p<0.05$, ${ }^{* *} p<0.01$, ${ }^{* * *} p<0.001$ versus corresponding WT (Student's t test, Fisher's exact probability test, or 2-way ANOVA followed by Bonferroni's test). $n=8-10$ animals per genotype.

Il1rapl1-KO mice required longer training to reach the criterion during acquisition compared with WT mice. There were fewer Il1 rapl1-KO mice reaching the criterion, compared with their littermates, on Days 6, 7, and 8. Accordingly, Il1rapl1-KO mice took more days to reach the criterion compared with WT mice $\left(t_{(18)}=2.689, p=0.014 ;\right.$ Fig. $\left.2 E\right)$. During the acquisition phase of the Morris water maze, two-way ANOVA revealed differences (genotype as between-subjects factor, $F_{(1,72)}=30.55, p<0.0001$; 
time as within-subjects factor, $F_{(3,72)}=15.03, p<0.0001$; genotype $\times$ time interaction, $\left.F_{(3,72)}=1.33, p=0.293\right)$. Bonferroni's post hoc test showed an increased latency in Il1 rapl1-KO mice to find the platform, as shown also by AUC $\left(t_{(18)}=4.21, p=0.01\right)$. In addition, Ill rapl1-KO mice spent significantly less time in the target zone during the probe test compared with WT mice (Fig. $2 F$ ). Finally, in the radial-maze task, Il1 rapl1-KO mice failed to perform correctly, as shown by the increased AUC of the total number of errors $\left(t_{(18)}=5.35, p=0.0005\right)$ and by the increased number of days to reach the criterion $\left(t_{(18)}=5.21, p=0.0006\right.$; Fig. 2G).

Thus our data strongly indicate that hippocampal-dependent memory is strongly impaired in Il1 rapll-KO mice.

Dendritic arborization complexity of hippocampal neurons is altered in Il1 rapl1-KO mice and in iPS cell-derived neurons from a patient with an ILIRAPL1 mutation

Our behavioral data indicate that hippocampal function is particularly impaired in Ill rapll-KO mice. We and others have previously demonstrated that IL1RAPL1 regulates excitatory synapse and dendritic spine formation in both hippocampal and cortical neurons (Pavlowsky et al., 2010a; Valnegri et al., 2011b; Yoshida et al., 2011). To better understand why hippocampal circuits are particularly affected in the Il1 rapl1-KO mice, we looked at neuronal and dendrite morphologies in both the hippocampus and cortex. Brains from 1-month-old and 3-month-old male WT and Il1 rapl1-KO mice (littermates) were subjected to Golgi staining. Sholl analysis was performed on pyramidal neurons from CA1, CA2, and occipital and parietal cortices to analyze dendritic arborization complexity. Branching points were counted for eight neurons for each brain field for 4-9 animals of each genotype and plotted on the distance from the soma using Neurostudio and Prism 5 software. We observed in adult Il1rapl1-KO mice, compared with adult WT mice, more branching points in hippocampal neurons of CA1 and CA2 fields (Fig. $3 A, B, D, E$ ). Meanwhile, the number of branching points of cortical neurons from WT and KO mice is comparable (Fig. $3 G, H$ ). Notably, the increased complexity of dendrite arborization in $\mathrm{KO}$ animals seems to be particularly evident in the first $50-100 \mu \mathrm{m}$ from the cell soma (Fig. 3C,F). Thus, our data indicate that the morphology of CA1 and CA2 hippocampal neurons is specifically altered in Il1 rapl1-KO mice.

We then asked whether a similar alteration in dendrite development was also present in neurons derived from iPS cells of a patient with IL1RAPL1 loss-of-function mutation (Ramos-Brossier et al., 2015). iPS cells obtained from skin fibroblasts of a healthy donor and Patient J, carrying the $\Delta$ exon 6 mutation in the IL1RAPL1 gene, were first characterized for the expression of pluripotent markers like Oct3/4, Lin28, Nanog, and Sox2 (Fig. 4A). Neuronal precursor cells (NPCs) obtained by the iPS cells were positive for neuronal markers Nestin and Sox2 (Fig. 4B) and neurons derived from NPCs showed electrophysiological properties like voltagegated currents and action potentials after $60 \mathrm{~d}$ of differentiation (Fig. 4C). We then checked for the expression of the IL1RAPL1 mRNA by real-time quantitative PCR in neuronal precursors obtained from Patient $\mathrm{J}$ and a healthy control using primers designed to span an exon-exon junction between exons 5 and 7-so as to detect the presence of exon 6 - and between exons 8-9-so as to recognize the expression of total IL1RAPL1 mRNA. We thus found that the cells from Patient J express IL1RAPL1 mRNA at a level similar to that of cells from the healthy control, but with exon 6 deleted (Fig. 4D,E). However, Western blot analysis with an antibody against the C-terminal region of IL1RAPL1 showed that cells from Patient J do not express IL1RAPL1 protein (Fig. $4 F$ ), supporting our data indicating that IL1RAPL1 protein deleted from the region encoded by exon 6 is unstable (RamosBrossier et al., 2015).

Then we performed a morphological analysis of the NPCderived neurons, counting the number of branching points, the total number of primary and secondary dendrites, and the total and average length of primary and secondary dendrites (Fig. 4G). Interestingly we found that the neurons from Patient J presented a more complex arborization with an increased number of branching points, primary dendrites, and secondary dendrites (Fig. 4H-J). Moreover, the average dendrite length in cells of Patient $\mathrm{J}$ was shorter than in cells of the healthy control (Fig. $4 K-N)$.

\section{Identification of IL1RAPL1 protein domains involved in regulating dendritic arborization complexity}

We then decided to identify which protein domain of IL1RAPL1 is required for regulating dendrite branching. Hippocampal neurons were transfected at DIV 11 with GFP alone or together with HA-IL1RAPL1, HA-IL1RAPL2, HA-IL1RAPL1 $\Delta$ N, HAIL1RAPL1 $\Delta$ exon6, HA-IL1RAPL1 C31R, HA-IL1RAPL1 $\Delta$ C, HA-IL1RAPL1 $\Delta 8$, HA-IL1RAPL1 1-558, or HA-IL1RAPL1 I643V and were fixed and stained at DIV 15 with anti-HA. Images obtained by confocal microscopy were subjected to Sholl analysis and branching points were quantified and plotted for distance from the soma.

We found that the overexpression of IL1RAPL1 induces a reduction in the number of branching points compared with the control (GFP-expressing neurons) and this effect is particularly evident in the first $50 \mu \mathrm{m}$ from the cell soma (Fig. 5A-C). Similarly, the overexpression of constructs that present mutations and deletions in the intracellular domains of IL1RAPL1 leads to fewer branching points. By contrast, the overexpression of IL1RAPL1 mutations affecting the extracellular domain does not have an effect on arborization (Fig. $5 A, B$ ). Thus, our data suggest that the extracellular part of IL1RAPL1 protein is required to regulate dendrite arborization.

To further confirm the role of the extracellular part of IL1RAPL1 in the simplification of dendritic arborization, we electroporated mice in utero (dal Maschio et al., 2012) to obtain the overexpression of HA-IL1RAPL1 full-length protein or HA-IL1RAPL1 C31R mutant (unable to modify dendrite morphology in cultured neurons; Fig. 5) in hippocampal and cortical neurons together with GFP. Brain slices from 3-month-old electroporated animals were stained with anti-GFP and anti-HA antibodies. Images obtained with a confocal microscope were analyzed for dendritic arborization complexity. Images were subjected to Sholl analysis and branching points were quantified and plotted for distance from the soma.

As in vitro, the number of branching points in hippocampal neurons is decreased in neurons overexpressing the full-length protein but not in the mutant HA-IL1RAPL1 C31R neurons (Fig. $6 A-D)$. The effect of simplification of dendrite complexity is particularly evident in the first $40-70 \mu \mathrm{m}$ from the cell soma (Fig. $6 D)$. In addition, overexpression of the full-length protein but not the C31R mutant reduces the total dendritic length in the hippocampus (Fig. 6C). In contrast, the overexpression of IL1RAPL1 in the cortex does not modify dendritic morphology (Fig. 6C). Thus, the overexpression of IL1RAPL1 affects dendrite development in the hippocampus in vivo, and the integrity of the extracellular domain of the protein is necessary for this effect. 
A

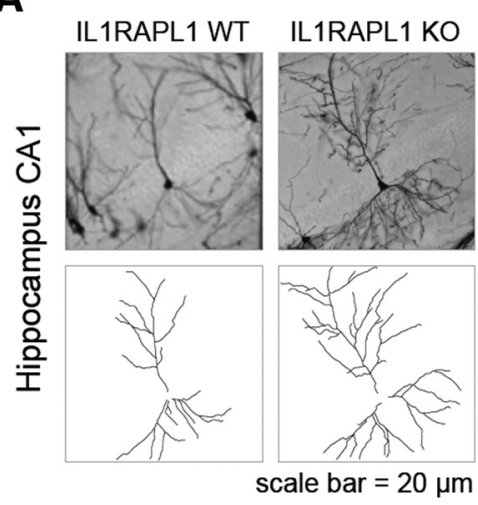

B

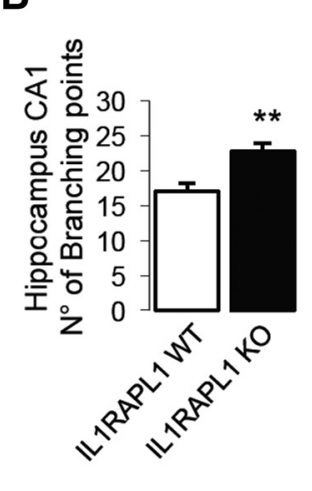

D

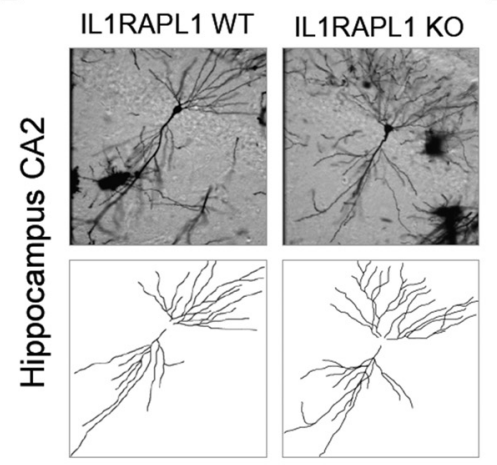

E

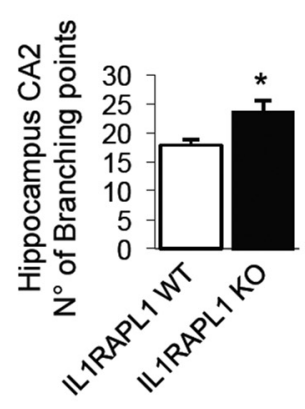

C

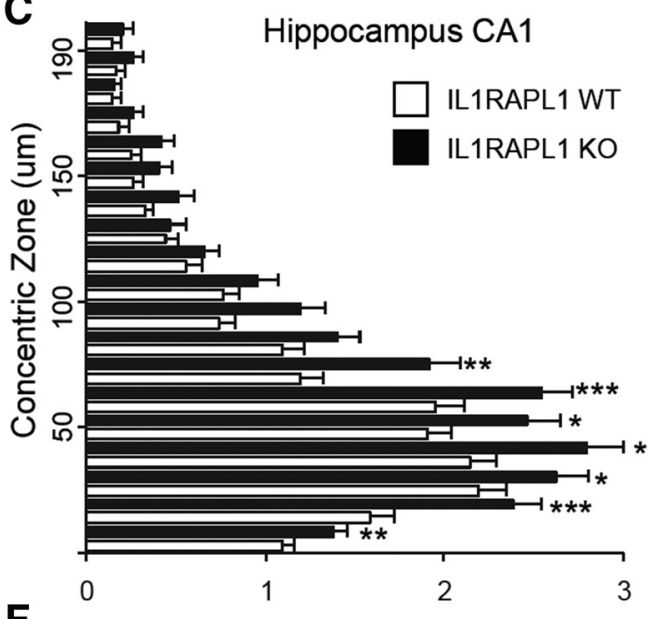

F

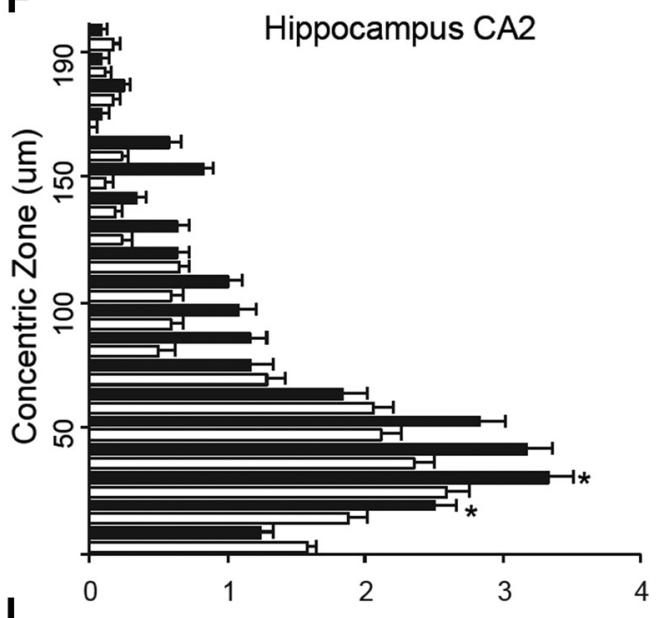

I

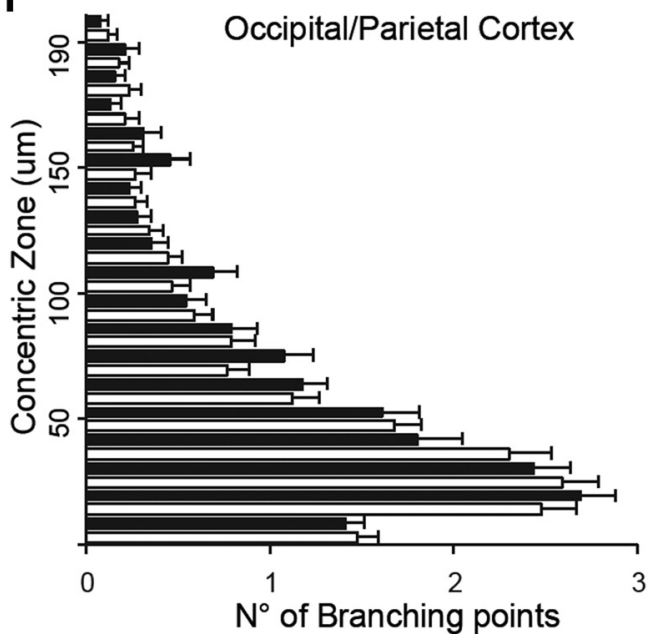

Figure 3. Dendritic arborization complexity of hippocampal neurons is altered in I/1rap/1-KO adult mice. $A, D, G$, Representative images of Golgi-stained pyramidal neurons from WT and II1rap/7-K0 mice in CA1 (A), CA2 (D), and occipital/parietal cortex $(\boldsymbol{G})$ and a schematization of their dendrites below. $\boldsymbol{B}, \boldsymbol{E}, \boldsymbol{H}$, The graphs show the quantification of total number of neuronal branching points from WT and /17rap/1-KO mice (8 neurons analyzed for each mouse; $N=4-9$ for each genotype) from $C A 1(\boldsymbol{B}), C A 2(\boldsymbol{E})$, and occipital/parietal cortex $(\boldsymbol{H})$. Data are shown as mean of number of branching points \pm SEM. ${ }^{*} p<0.05,{ }^{* *} p<0.005$ vs corresponding WT, Student's $t$ test. C, F, I, Quantification of the number of branching points from WT and II rapl1-K0 mice plotted on the distance from the soma $(\mu \mathrm{m})$. All values represent mean of total branching points every $10 \mu \mathrm{m} \pm \mathrm{SEM} .{ }^{*} p<0.05,{ }^{* *} p<0.005,{ }^{* * *} p<0.001$ vs corresponding WT, Student's $t$ test.

IL1RAPL1 regulates dendrite arborization complexity before synaptogenesis

Given that the only known interactor of IL1RAPL1 extracellular domain is $\operatorname{PTP} \delta$, we decided to explore whether this transinteraction could affect dendrite arborization. In vitro, the synaptogenesis process starts after DIV 4 (Gerrow et al., 2006).
Thus, we decided to study immature neurons to exclude the synaptogenic role of trans-synaptic interaction between IL1RAPL1 and PTP $\delta$ in the IL1RAPL1-mediated effect on dendrite arborization.

Hippocampal neurons were transfected at DIV 1 with GFP alone or in combination with HA-IL1RAPL1, HA-IL1RAPL1 
A
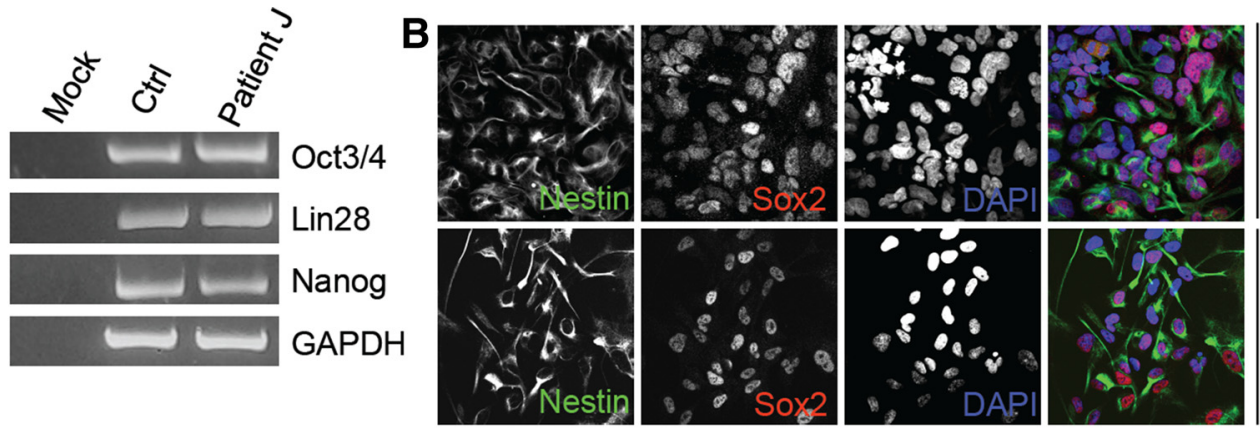

Ctrl
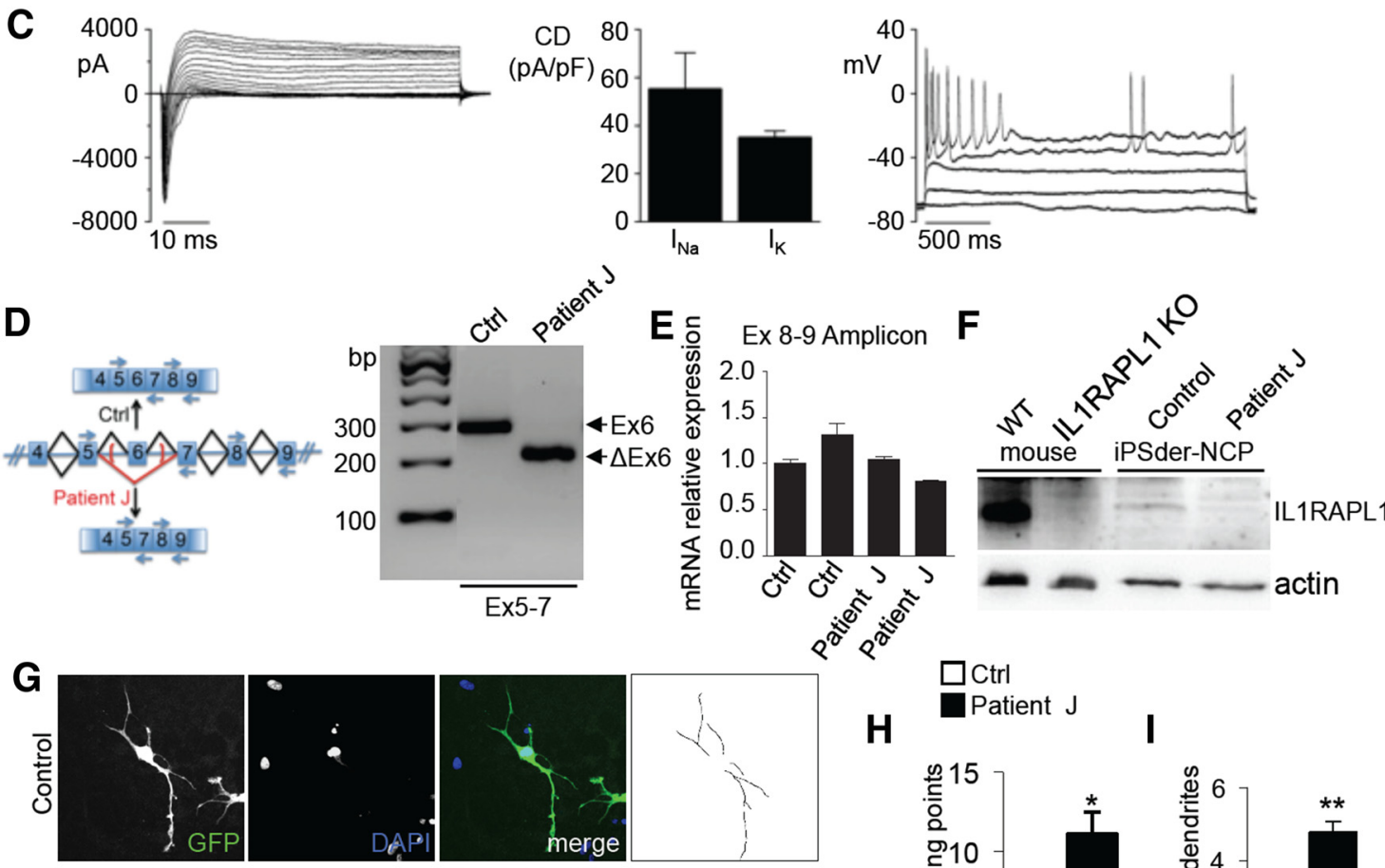

\section{H}

Patient J
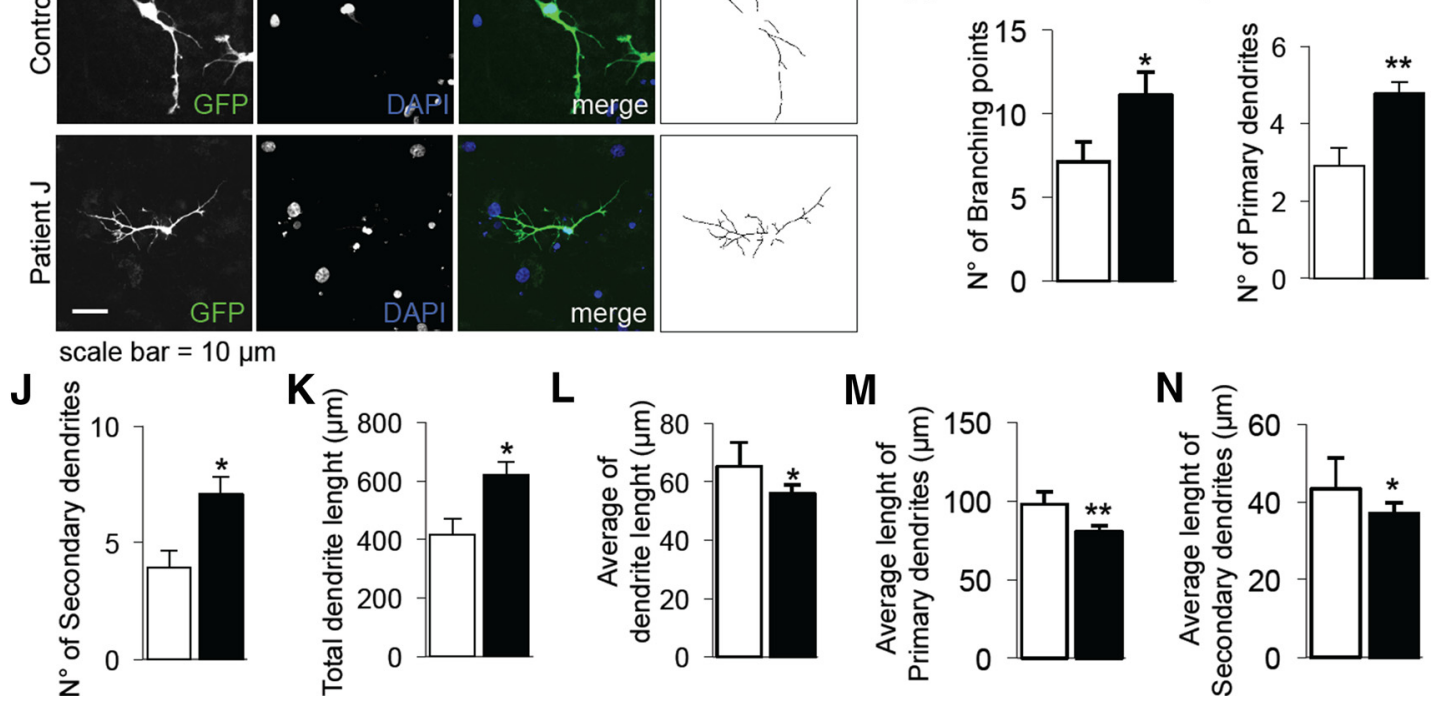

Figure 4. Dendritic arborization complexity is altered in iPS cells derived from patient carrying a mutation in IL1RAPL1 gene. $A$, $B$, Characterization of iPS cells $(\boldsymbol{A})$ and neuronal precursors $(\boldsymbol{B})$ from healthy donor and Patient J carrying mutation in ILIRAPL1 gene. C, Left, Total voltage-gated current traces recorded from a representative differentiated neuron by applying a depolarizing voltage step protocol from a holding potential of $-70 \mathrm{mV}$. Seventy-seven percent (10 of 13) of the recorded neurons express $\mathrm{Na}^{+}$and $\mathrm{K}^{+}$currents. Bar graph (center) shows mean $\mathrm{Na}^{+}$and $\mathrm{K}^{+}$current densities measured at -20 and $+20 \mathrm{mV}$, respectively. Right, Action potentials recorded from the same differentiated neuron in the left panel by injecting depolarizing currents of increasing amplitude from a resting potential of $-70 \mathrm{mV} . \boldsymbol{D}, \boldsymbol{E}, \mathrm{mRNA}$ expression analysis of ILIRAPL1 gene in neural precursor derived from healthy donor and Patient J carrying the $\Delta$ exon 6 mutation in IL7RAPL1 gene shows that in Patient J, exon 6 is specifically deleted (D) but the total expression levels of the WT and mutated mRNA are similar (E). Data are shown as mean \pm SEM of three independent experiments. $\boldsymbol{F}$, Western blot analysis of neural precursor derived from healthy donor and Patient $J$ carrying the $\Delta$ exon 6 mutation in IL1RAPL1 gene shows that the expression of IL1RAPL1 protein is absent in the neural precursor derived from Patient J; for comparison, the expression of IL1RAPL1 protein in brain extracts of WT and I/1 rap/1-K0 mice is shown in the two first lanes. G, Representative images of iPS cell-derived neurons from healthy donor and Patient J (III-2) and a schematization of their dendrites on the right. $\boldsymbol{H}-\boldsymbol{N}$, Analysis of the morphology of iPS cell-derived neurons from healthy donor and Patient $J$ ( 15 neurons analyzed for each condition in 3 independent experiments). We evaluated the number of branching points $(\boldsymbol{H})$, the number of primary $(\boldsymbol{I})$ and secondary $(\boldsymbol{J})$ dendrites, total $(\boldsymbol{K})$ and average $(\boldsymbol{L})$ dendrite length, the average length of primary $(\boldsymbol{M})$ and secondary $(\boldsymbol{N})$ dendrites. Data are shown as mean \pm SEM. ${ }^{*} p<0.05$, ${ }^{* *} p<0.005$ vs Ctrl, Student's $t$ test. 
A
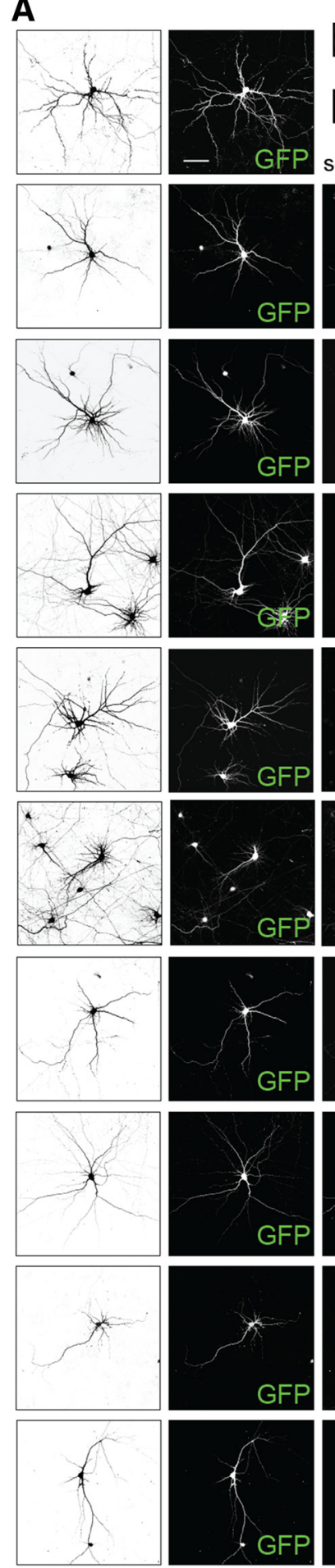

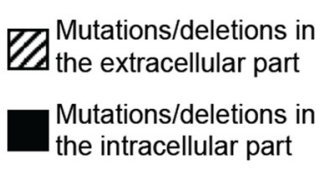

scale bar $=20 \mu \mathrm{m}$
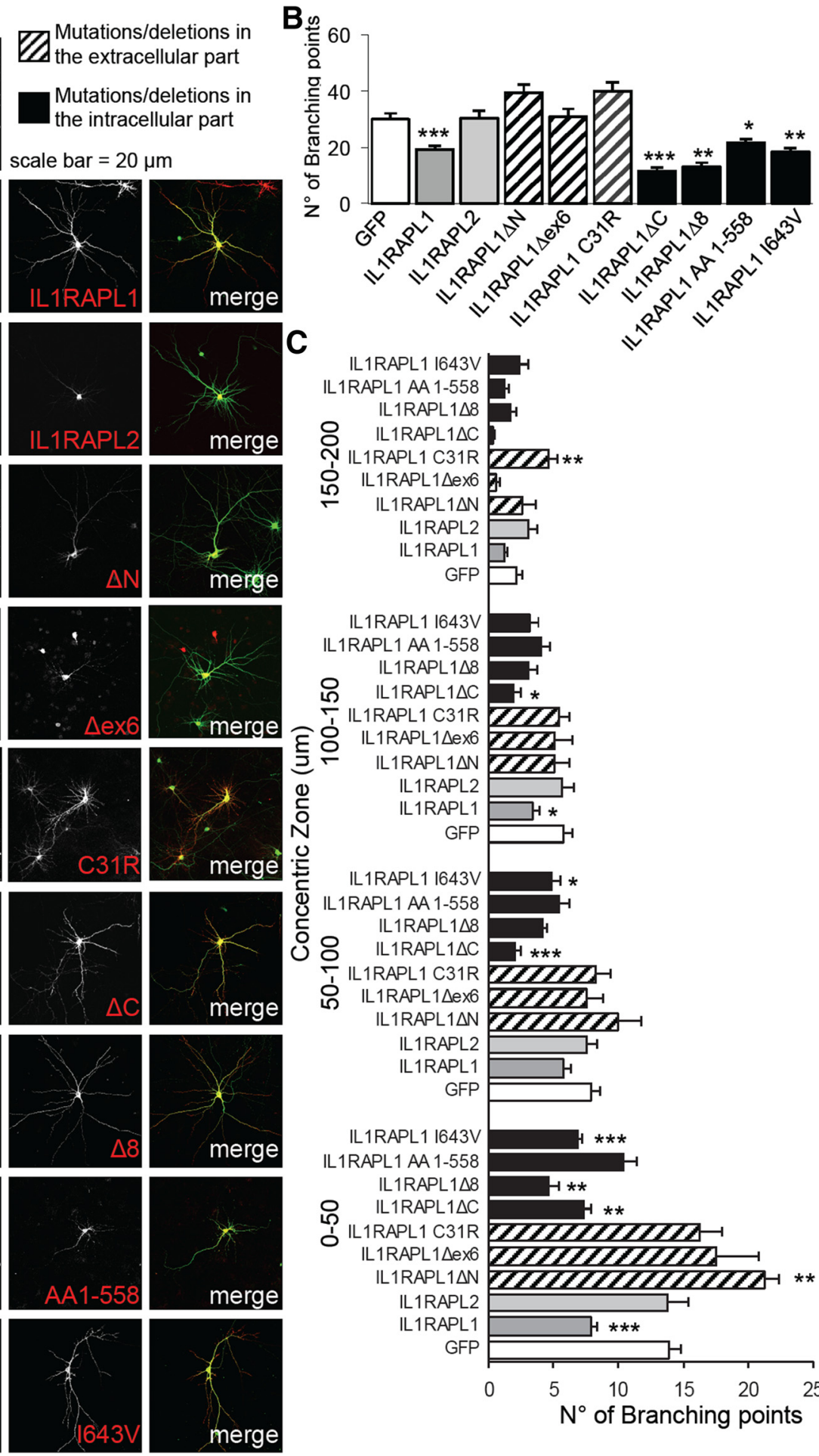

\section{IL1RAPL1 $1643 \mathrm{~V}$
IL1RAPL1 AA 1-558 \\ IL1RAPL1 188 - \\ 은 IL1RAPL1 $\triangle \mathrm{C}$}

ㄱ. IL1RAPL1 C31R

은 IL1RAPL1 $\triangle \mathrm{ex6}$

ㄴ) IL1RAPL1 $1 \Delta \mathrm{N}$

IL1RAPL2

IL1RAPL1

GFP

IL1RAPL1 I643V

IL1RAPL1 AA 1-558

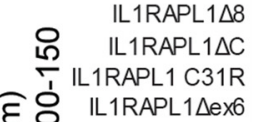

छㅇㅇㅇ IL1RAPL1 1 $\mathrm{ex6}$

ํㅡㅁ

IL1RAPL1 $1 \mathrm{~N}$
IL1RAPL2
IL1RAPL1
GFP

IL1RAPL1 I643V

ఖ IL1RAPL1 AA 1-558

IL1RAPL1 $\triangle 8$

O O IL1RAPL1 $\triangle C$

ㅎํ IL1RAPL1 C31R
IL1RAPL1 1 ex6

IL1RAPL1 $\triangle N$

IL1RAPL2

IL1RAPL1

GFP

IL1RAPL1 I643V

IL1RAPL1 AA 1-558

IL1RAPL1 $\triangle 8$

은 RAPL1 $\triangle C$

ơ IL1RAPL1 C31R

IL1RAPL1 $\triangle N$

IL1RAPL2

IL1RAPL1

GFP
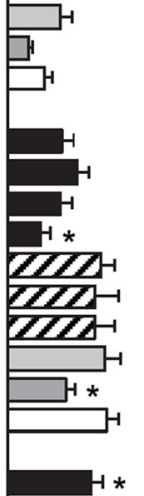

Figure 5. Identification of IL1RAPL1 protein domains involved in regulating dendritic arborization complexity in rat hippocampal neurons. $A$, Primary hippocampal neurons were transfected at DIV 11 with GFP alone or together with HA-IL1RAPL1, HA-IL1RAPL2, HA-IL1RAPL1 $\Delta \mathrm{N}(\Delta \mathrm{N})$, HA-IL1RAPL1 $\Delta$ exon6 ( $\Delta$ ex6), HA-IL1RAPL1 C31R (C31R), HA-IL1RAPL1 $\Delta C(\Delta C)$, HA-IL1RAPL1 88 ( $\Delta 8$ ), HA-IL1RAPL1 1-558 (AA1-558), or HA-IL1RAPL1 1643V (I643V). At DIV 14-15 neurons were fixed and stained with anti-HA. GFP signal (left) was used for the Sholl analysis. B, Quantification of total number of branching points of neurons overexpressing IL1RAPL1 constructs (15 neurons from 3 independent experiments were analyzed for each construct). All values represent mean \pm SEM. ${ }^{*} p<0.05,{ }^{* *} p<0.005,{ }^{* * *} p<0.001$ vs GFP, ANOVA followed by Tukey's post hoc test. C, Quantification of number of branching points of neurons overexpressing IL1RAPL1 constructs plotted for distance from the soma $(\mu \mathrm{m})$. All values represent mean of total branching points every $50 \mu \mathrm{m} \pm \mathrm{SEM} .{ }^{*} p<0.05,{ }^{* *} p<0.005,{ }^{* * *} p<0.001$ vs GFP, ANOVA followed by Tukey's post hoc test.

C31R, HA-IL1RAPL1 $\Delta 8$, or HA-IL1RAPL1 I643V, and were fixed and stained at DIV 4 with an anti-HA antibody (Fig. 7A). The total number of primary and secondary dendrites and the total and average length of primary and secondary dendrites of transfected neurons were measured. As observed in mature neu- rons, the overexpression of IL1RAPL1 in immature neurons leads also to a simplification of dendritic arborization: the total number of primary dendrites is lower compared with those of the control (GFP-overexpressing neurons) and, for this effect, the extracellular domain of IL1RAPL1 is still required (Fig. $7 B-D$ ). 
A

scale bar $=20 \mu \mathrm{m}$
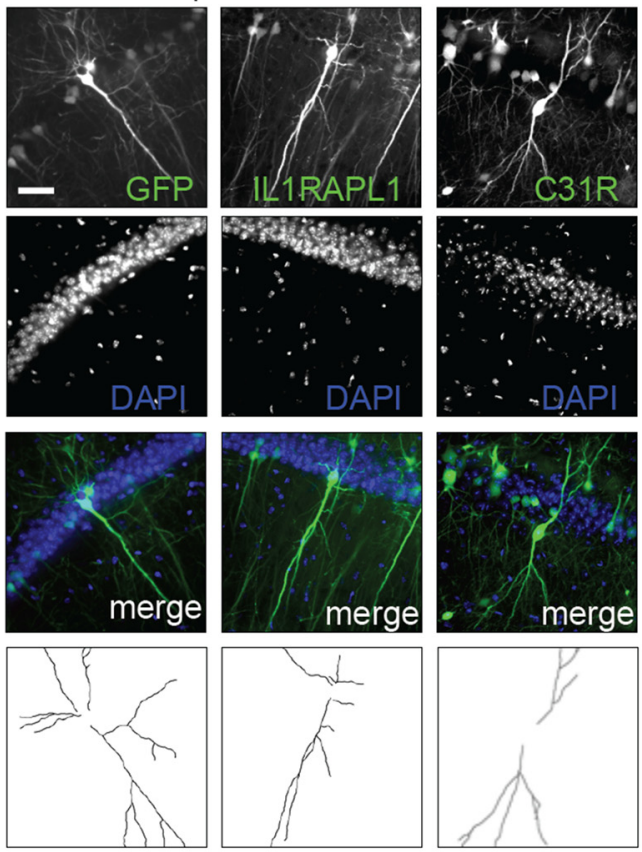

B
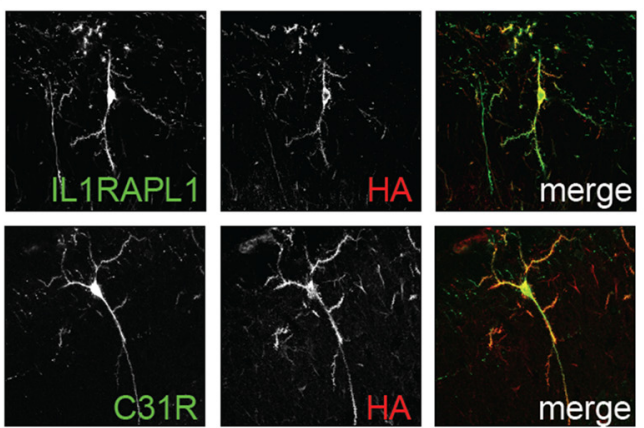

C

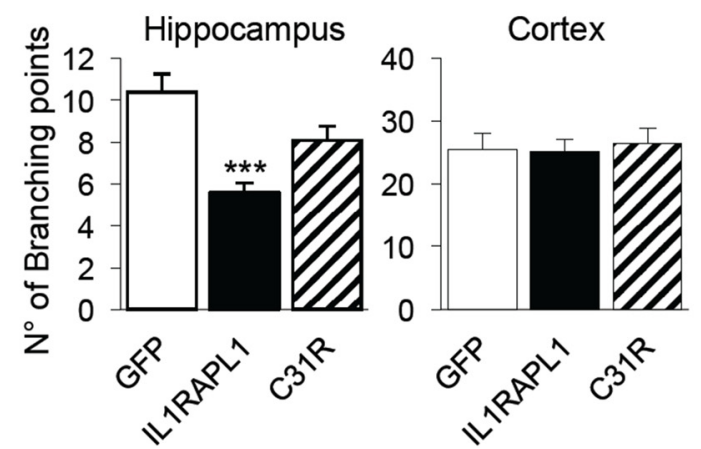

D

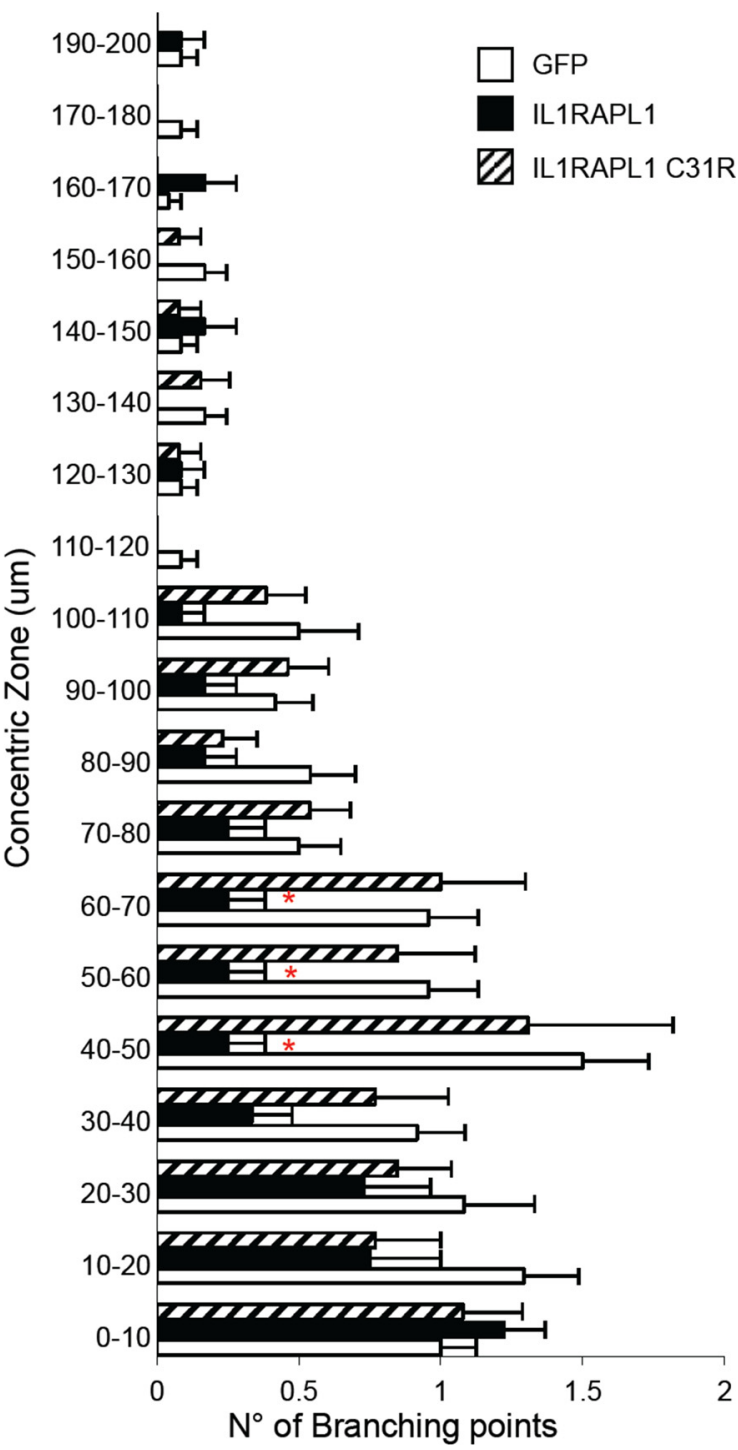

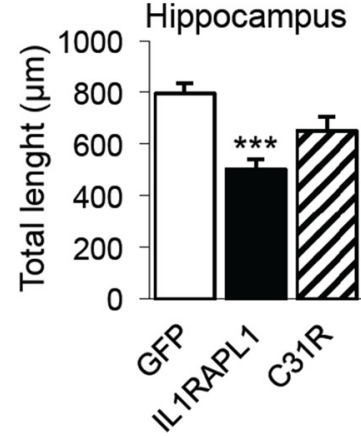

Cortex

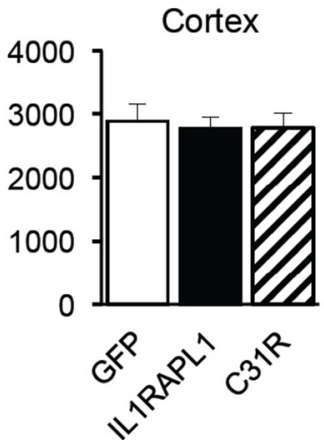

Figure 6. IL1RAPL1 regulates hippocampal dendritic arborization in vivo. A, Example images of hippocampal neurons overexpressing GFP alone or together with full-length GFP-HA-IL1RAPL1 or GFP-HA-IL1RAPL1 C31R mutant from brain slices from 3-month-old in utero electroporated mice, with schematization of their dendrites below. $\boldsymbol{B}$, Brain slices from in utero electroporated mice were stained with anti-GFP and anti-HA antibody (red signal) to show the expression of transfected IL1RAPL1 constructs. C, $\boldsymbol{D}$, Confocal microscope images of transfected hippocampal and cortical neurons ( 5 neurons from 4 mice for each condition) were analyzed for dendritic arborization complexity using Sholl analysis on GFP signal. Branching points and dendritic lengths were quantified ( $\boldsymbol{C}$; all values represent mean \pm SEM, ${ }^{*} p<0.05,{ }^{* * *} p<0.001$ vs GFP, ANOVA followed by Dunnet's post hoc test) and plotted for the distance from the soma (D). All values represent mean of total branching points every $10 \mu \mathrm{m} \pm \mathrm{SEM},{ }^{*} p<0.05$ vs GFP, ANOVA followed by Dunnet's post hoc test.

These data suggest that the IL1RAPL1-mediated simplification of dendrite arborization is probably not a secondary consequence of the trans-synaptic interaction between IL1RAPL1 and PTP $\delta$.
PTP $\delta$ and IL1RAPL1 cis-interaction

Although PTP $\delta$ has been shown to localize in axons, we tested whether a possible cis-interaction between IL1RAPL1 and PTP $\delta$ in dendrites can mediate the IL1RAPL1 effect on dendrite 
A
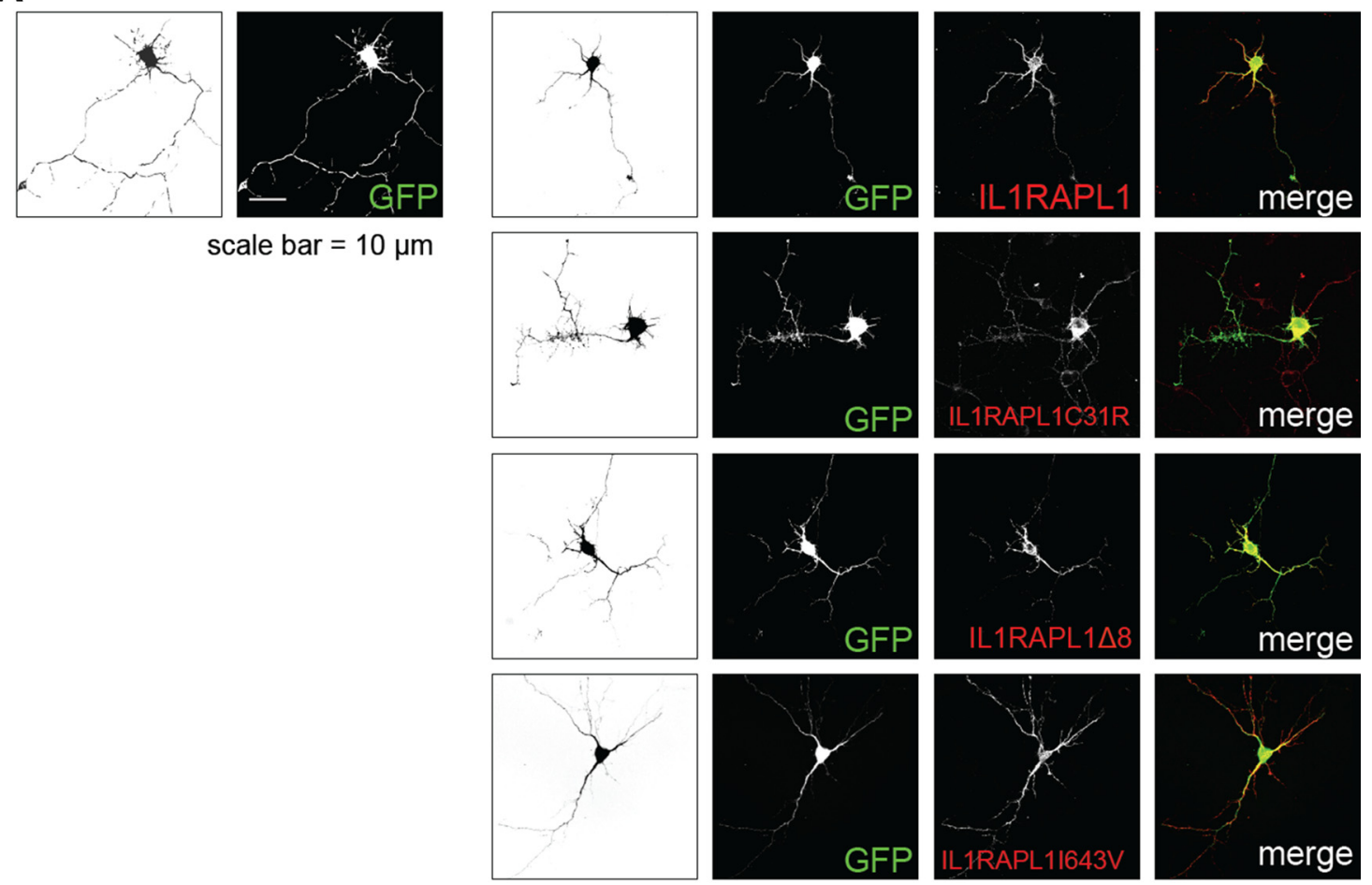

B

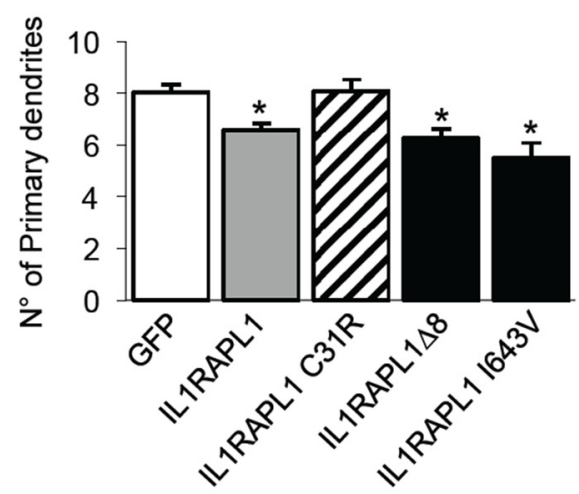

D

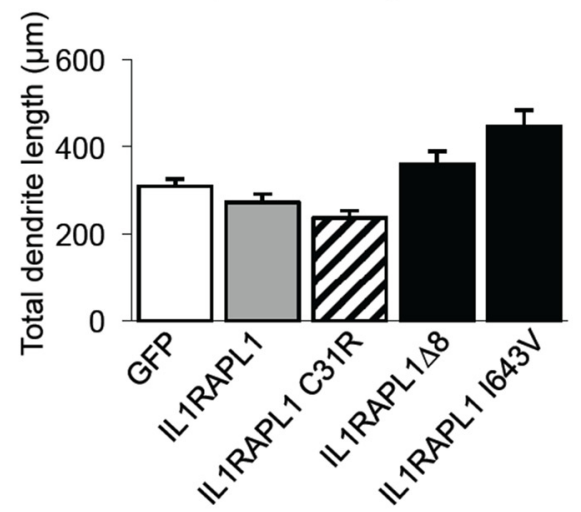

C

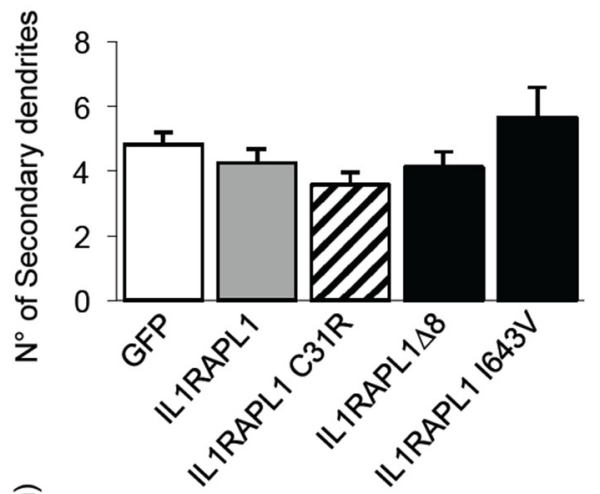

E

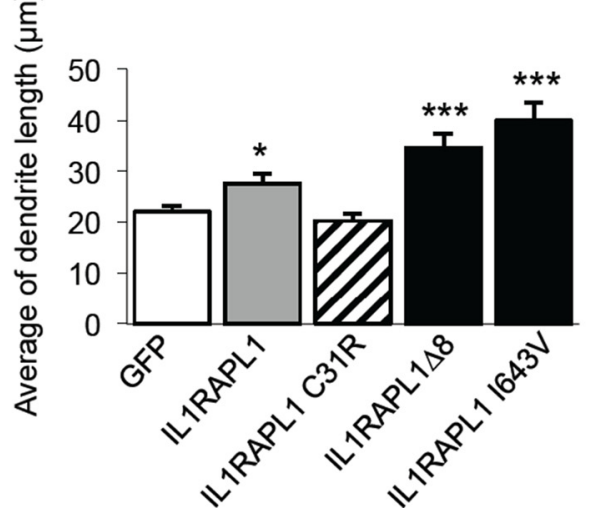

Figure 7. IL1RAPL1 regulates dendrite arborization complexity before synaptogenesis. A, Hippocampal neurons were transfected at DIV 1 with GFP alone or in combination with HA-IL1RAPL1, HA-IL1RAPL1 C31R, HA-IL1RAPL1 $\Delta 8$, or HA-IL1RAPL1 I643V, and were fixed and stained at DIV 4 with anti-HA antibody. GFP signal (left) was used for the morphological analysis of the cells. $\boldsymbol{B}-\boldsymbol{E}$, The graphs show the quantification of primary $(\boldsymbol{B})$ and secondary $(\boldsymbol{C})$ dendrites, and total $(\boldsymbol{D})$ and average $(\boldsymbol{E})$ length of primary and secondary dendrites of neurons overexpressing IL1RAPL1 constructs. Ten to 15 neurons were analyzed for each construct in three independent experiments. All values represent mean \pm SEM. ${ }^{*} p<0.05,{ }^{* * *} p<0.005$ vs GFP, ANOVA followed by Dunnet's post hoc test.

arborization. We transfected neurons with GFP alone or with HA-IL1RAPL1, HA-PTP $\delta$, HA-PTP $\delta$ ECTO, HA-PTP $\delta$ A-B(HA-PTP $\delta$ without miniexons $\mathrm{A}$ and $\mathrm{B}$ ) and shRNA against $\operatorname{PTP} \delta$ (Yoshida et al., 2011) and IL1RAPL1 in combination with
HA-PTP $\delta$, HA-PTP $\delta$ ECTO, and HA-PTP $\delta$ A-B- at DIV 11. We used the HA-PTP $\delta \mathrm{A}-\mathrm{B}-$ construct, which expresses PTP $\delta$ with miniexons $A$ and $B$ deleted and is unable to bind IL1RAPL1 with a trans-interaction (Yoshida et al., 2011). We then fixed and 
A

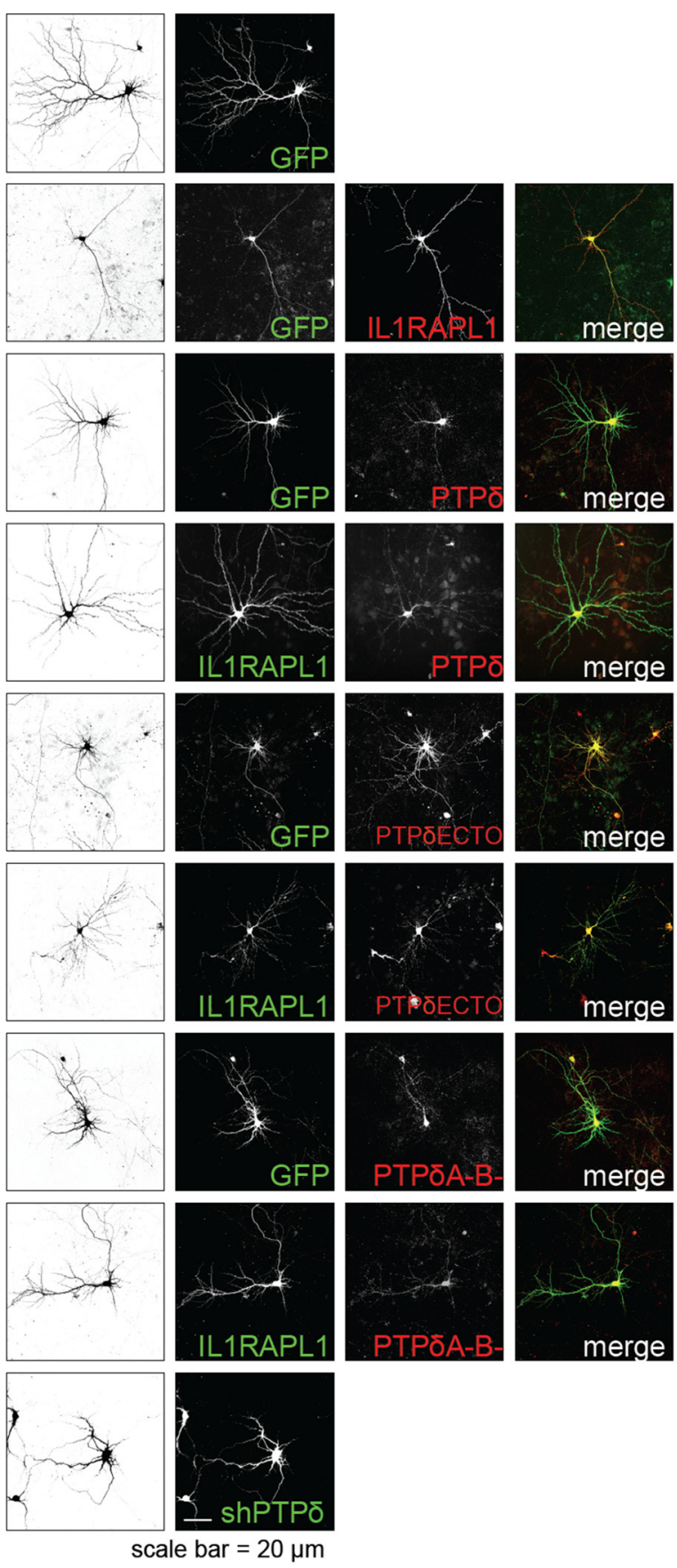

$\mathbf{B}_{50}$

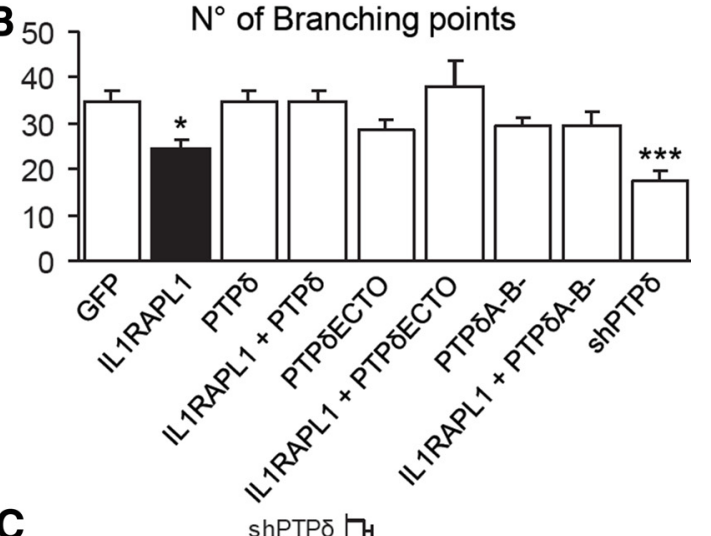

C

ণั

IL1RAPL1 + PTP

РТРБА-B-

IL1RAPL1 + PTPסECTO

PTPठECTO

IL1RAPL1 + PTPס

PTPס

IL1RAPL1

GFP

ShPTPס

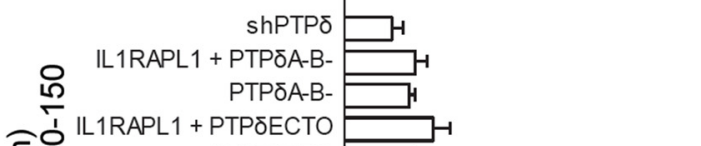

L1RAPL1 + PTPס

PTPס

IL1RAPL1

GFP

shPTP

IL1RAPL1 + PTPסA-B

РТРठА-B-

נo

官

1RAPL1 + PTPסECTO

PTPסECTO

IL1RAPL1 + PTP

PTPठ

IL1RAPL

GFP

FP

PTPסA-B-
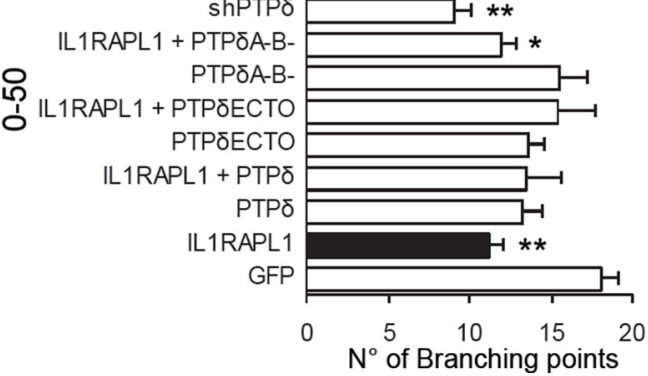

Figure 8. PTP $\delta$ and IL1RAPL1 cis- interaction blocks the ability of IL1RAPL1 to regulate dendrite morphology. $\boldsymbol{A}$, Hippocampal neurons were transfected at DIV 11 with GFP alone or with HA-IL1RAPL1, HA-PTP $\delta$, HA-PTP $\delta$ ECT0, HA-PTP $\delta$ A - B - and shRNA against PTP $\delta$ and IL1RAPL1 in combination with HA-PTP $\delta$, HA-PTP $\delta$ ECT0, and HA-PTP $\delta$ A - B - and then fixed and stained at DIV $14-15$ with anti-HA and anti-IL1RAPL1 antibodies. GFP signal (left) was used for the Sholl analysis. $B$, Quantification of branching points of neurons overexpressing the indicated constructs. Ten to 15 neurons analyzed for each construct in three independent experiments. All values represent mean \pm SEM. ${ }^{*} p<0.05,{ }^{* * *} p<0.001$ vs GFP, ANOVA followed by Dunnet's post hoc test. C, Quantification of branching points of neurons overexpressing the indicated combination of constructs plotted for distance from the soma ( $\mu \mathrm{m}$ ). All values represent mean of total branching points every $50 \mu \mathrm{m} \pm$ SEM. ${ }^{*} p<0.05,{ }^{* *} p<0.005$ vs GFP ANOVA followed by Dunnet's post hoc test.

stained neurons at DIV 14-15 with anti-HA and anti-IL1RAPL1 antibodies (Fig. 8A). Images obtained by confocal microscopy were subjected to Sholl analysis and branching points were quantified and plotted for distance from the soma. The analysis showed that the co-overexpression of full-length PTP $\delta$, РTP $\delta$
$\mathrm{A}-\mathrm{B}-$, and PTP $\delta$ ECTO block the ability of overexpressed IL1RAPL1 to reduce the number of branching points.

Otherwise the shRNA-mediated silencing of PTP $\delta$ protein, like the overexpression of IL1RAPL1, leads to the simplification of dendrite arborization (Fig. $8 B, C$ ). 
This indicates that a cis-interaction between IL1RAPL1 and $\operatorname{PTP} \delta$ can occur in the dendrite compartment and can block the effect of IL1RAPL1 on dendrites. This antagonistic effect of PTP $\delta$ is also confirmed by the effect of its silencing that mimics the effect of IL1RAPL1 overexpression on dendrites. The extracellular part of PTP $\delta$ seems to be sufficient to block the IL1RAPL1 effect and the absence of PTP $\delta$ miniexons $\mathrm{A}$ and $\mathrm{B}(\mathrm{PTP} \delta \mathrm{A}-\mathrm{B}-$ ) does not affect the PTP $\delta$ capacity of IL1RAPL1 blockade, even if in the first $50 \mu \mathrm{m}$ from the cell soma there is a reduction in the number of branching points in neurons overexpressing IL1RAPL1 together with HA-PTP $\delta$ A-B - . Possibly, the role of the miniexons in the IL1RAPL1-PTP $\delta$ interaction (Yoshida et al., 2011) is less important in cis than in trans.

To better characterize the cis-interaction between IL1RAPL1 and PTP $\delta$ we looked at the localization of overexpressed PTP $\delta$ on the dendrite membrane surface by itself or in combination or IL1RAPL1. Hippocampal neurons were transfected at DIV 11 with GFP, HA-IL1RAPL1, and IL1RAPL1 in combination with HA-PTP $\delta$ and HA-PTP $\delta A-B-$. HA-TSPAN7, a transmembrane protein that does not interact with IL1RAPL1, has been used as negative control. At DIV 14-15, live hippocampal neurons were stained for $10 \mathrm{~min}$ at $37^{\circ} \mathrm{C}$ with anti-HA-tag rabbit antibody to label overexpressed protein on the membrane surface (Fig. 9A). After washing, neurons were fixed and incubated with anti-HA-tagged mouse antibody in permeabilizing condition. Then primary antibodies were labeled with FITC-conjugated and Cy3-conjugated secondary antibodies. The ratio of integrated intensity of surface HA signal per total HA signal was measured for each neuron (Fig. 9B).

As has been demonstrated in previous reports (Pavlowsky et al., 2010a; Valnegri et al., 2011b), IL1RAPL1 is clearly present in dendrites and on the cell surface. In contrast, overexpressed PTP $\delta$ is mostly localized in the axon at DIV 14 (Dunah et al., 2005; Takahashi et al., 2011) and the relative abundance of protein on the dendrite cell surface is low. The co-overexpression of IL1RAPL1 with PTP $\delta$ leads to an increased amount of PTP $\delta$ on the dendrite cell surface, showing a probable cis-interaction in dendrites between the two proteins (Fig. 9A,B). Neurons overexpressing PTP $\delta \mathrm{A}-\mathrm{B}-$ show a more equal distribution of the protein between axonal and dendrite compartments in respect to PTP $\delta$, but the distribution is not changed after IL1RAPL1 co-overexpression (Fig. $9 A, B)$. This experiment suggests that overexpressed PTP $\delta$ can be recruited from the axon to dendrites by a cis-interaction with IL1RAPL1. Moreover, dendritic PTP $\delta$ is probably able to block the effect of IL1RAPL1 on dendritic arborization.

To better demonstrate a possible cis-interaction between IL1RAPL1 and $\operatorname{PTP} \delta$, we performed two experiments in heterologous cells. First, we tested the possible IL1RAPL1 and PTP $\delta$ cis-interaction with a coimmunoprecipitation experiment. COS-7 cells were cotransfected with IL1RAPL1 and HA-PTP $\delta$ or HA-PTP $\delta$ A-B-. Cell lysates obtained from transfected cells were immunoprecipitated with anti-HA antibodies. As shown in the Figure 9 C, IL1RAPL1 was coimmunoprecipitated together with both PTP $\delta$ and HAPTP $\delta \mathrm{A}-\mathrm{B}-$. However, we reasoned that part of the IL1RAPL1$\mathrm{PTP} \delta$ interaction we revealed by the coimmunoprecipitation might be mediated also by the trans-interaction between the two proteins. For this reason, we performed a second experiment where we analyzed the IL1RAPL1 and PTP $\delta$ cis-interaction with a coclustering experiment. COS-7 cells were cotransfected with IL1RAPL1 and HA-PTP $\delta$ or HA-PTP $\delta$ A-B - and stained with anti-HA antibodies to label PTP $\delta$ or PTP $\delta \mathrm{A}-\mathrm{B}-$ and antiIL1RAPL1 antibodies to label IL1RAPL1. Also with this experiment we found that both $\mathrm{PTP} \delta$ and $\mathrm{PTP} \delta \mathrm{A}-\mathrm{B}-$ were redistributed in the cells to form clusters with IL1RAPL1 (Fig. 9C). Thus, all these data strongly suggest that IL1RAPL1 can interact in cis- with PTP $\delta$. Interestingly, our data also suggest that the deletion of the A and $\mathrm{B}$ exons does not abolish the interaction in cis- with IL1RAPL1.

IL1RAPL1 mediates the recruitment of presynaptic compartment, and knocking-down or overexpressing IL1RAPL1 decreases or increases excitatory synapse formation respectively (Valnegri et al., 2011b; Yoshida et al., 2011).

To evaluate the inhibitory effect of PTP $\delta$ on presynaptic recruitment, mediated by the cis-interaction with IL1RAPL1 in dendrites, hippocampal neurons were transfected at DIV 11 with GFP or HA-IL1RAPL1 alone or in combination with HA-PTP $\delta$ or HA-PTP $\delta \mathrm{A}-\mathrm{B}-$. Cells were fixed at DIV $14-15$ and stained with anti-HA and anti-Bassoon antibodies (Fig. 10A). Bassoon cluster intensity in neurons overexpressing IL1RAPL1, PTP $\delta$, and PTP $\delta \mathrm{A}-\mathrm{B}-$ was evaluated.

Our results show that the overexpression of full-length PTP $\delta$ or PTP $\delta$ lacking miniexons A and B does not affect the recruitment of excitatory presynapses. However, PTP $\delta$ constructs are able to block the IL1RAPL1-mediated recruitment of the excitatory presynaptic compartment (Fig. 10A,B). Our data indicate that the cis-interaction between IL1RAPL1 and PTP $\delta$ constructs involves their extracellular domains and blocks the effect of IL1RAPL1 on dendrites and on presynapses.

\section{IL- $1 \beta$ regulation of dendrite morphology is mediated by IL1RAPL1}

Previous work has demonstrated that IL- $1 \beta$ regulates dendrite morphology of cultured hippocampal neurons (Mishra et al., 2012; Xiao et al., 2015). We also previously demonstrated that IL- $1 \beta$-induced activation of JNK in hippocampal neurons is mediated by IL1RAPL1 (Pavlowsky et al., 2010b). We thus tested whether IL-1 $\beta$ 's ability to regulate dendrite morphology is mediated by IL1RAPL1. Hippocampal cultured neurons from WT and Ill rapl1-KO mice were treated with $10 \mathrm{ng} / \mathrm{ml} \mathrm{IL}-1 \beta$ for $72 \mathrm{~h}$. The treatments were done at DIV 2 or 11 and neurons were fixed at DIV 5 and 14 respectively. As previously demonstrated (Gilmore et al., 2004), the treatment with IL-1 $\beta$ in WT neurons is able to decrease dendrite complexity by reducing the number of primary dendrites and branching points in neurons at both DIV 5 and 14 (Fig. 11A-D). At DIV 5, IL-1 $\beta$ also increases the mean dendrite length (Fig. $11 A, B$ ). Confirming our in vivo observations, cultured hippocampal neurons from Il1 rapl1-KO mice have more primary dendrites at DIV 5 and branching points at DIV 14 and shorter dendrites at DIV 5 (Fig. 11C,D) compared with WT neurons. However, IL- $1 \beta$ treatment was unable to modify the dendrite morphology of Il1 rapl1-KO-derived hippocampal neurons. Our data point out that IL1RAPL1 is required for IL- $1 \beta$ regulation of dendrite morphology.

\section{Discussion}

Dendrites must satisfy many physiological requirements to ensure proper neuronal function. Numerous molecules and pathways are involved in correct dendrite development, maintenance, and function. For instance, actin and microtubules are the major structural components that underlie dendrite morphology. Regulators of actin and microtubule dynamics therefore have important roles in dendrite morphogenesis (Newey et al., 2005; Stuart and Spruston, 2015; Martínez-Cerdeño, 2017). Furthermore, in vivo and in vitro studies indicate that synaptic activity, growth factors, and contact-mediated proteins promote dendritic arbor elaboration and stabilization (McAllister, 2000; Foa et al., 2001; Arikkath, 2012; Valnegri et al., 2015). 
A
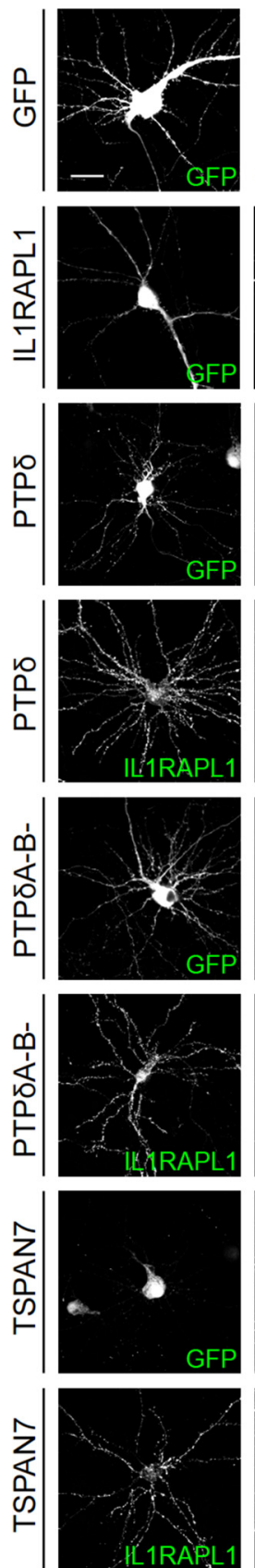

scale bar $=20 \mu \mathrm{m}$
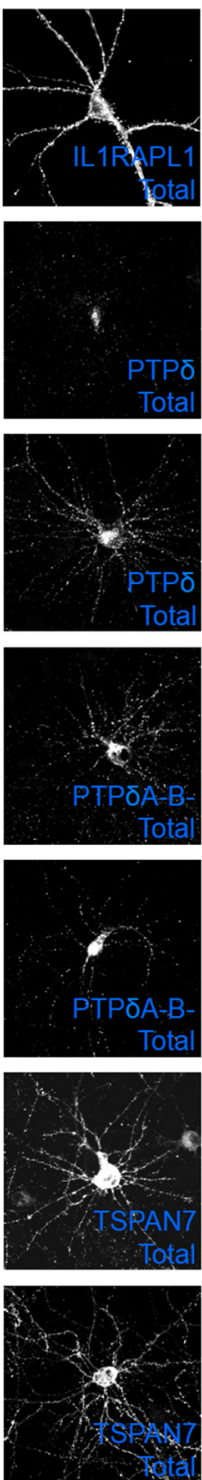
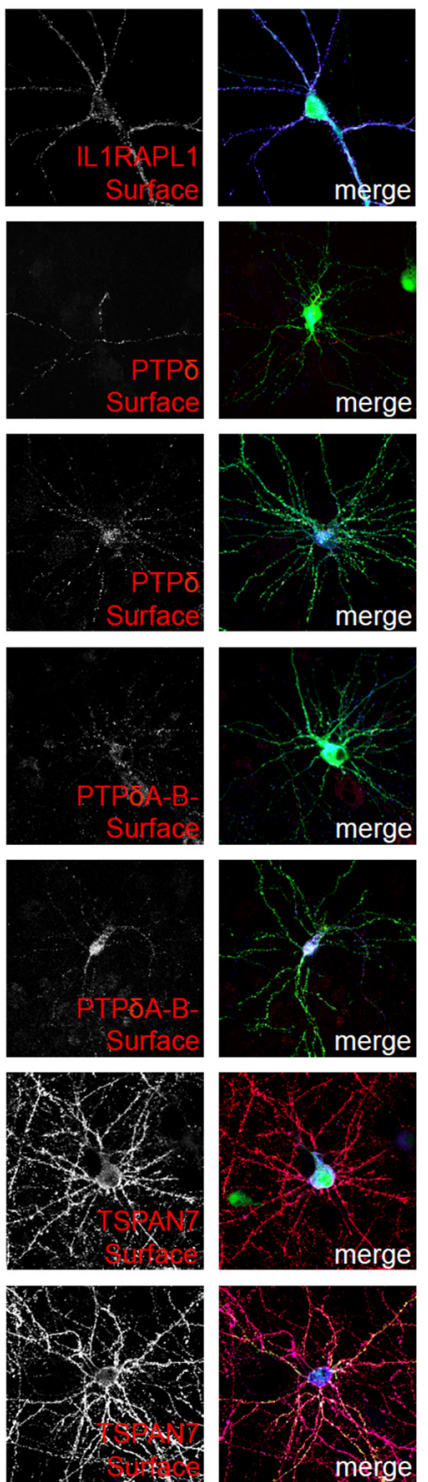

B
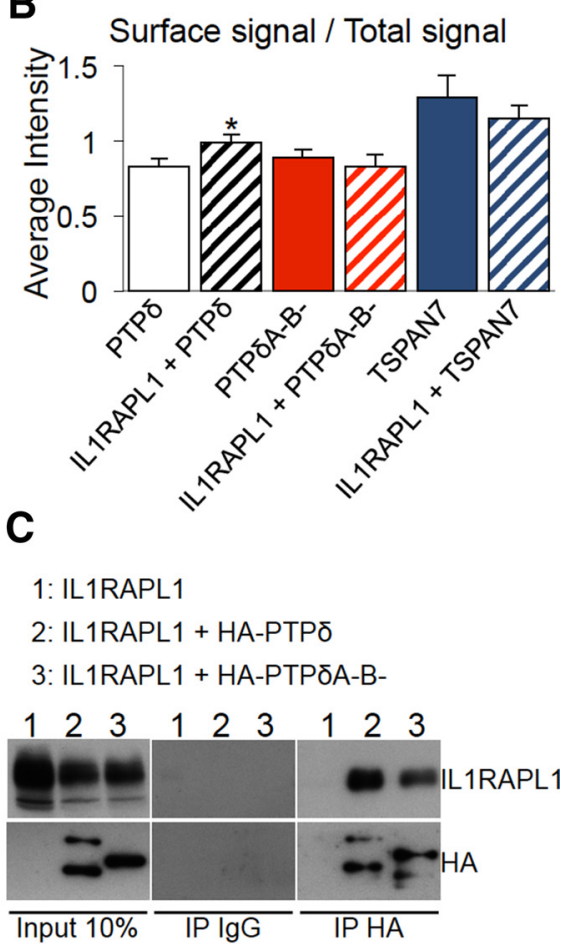

D

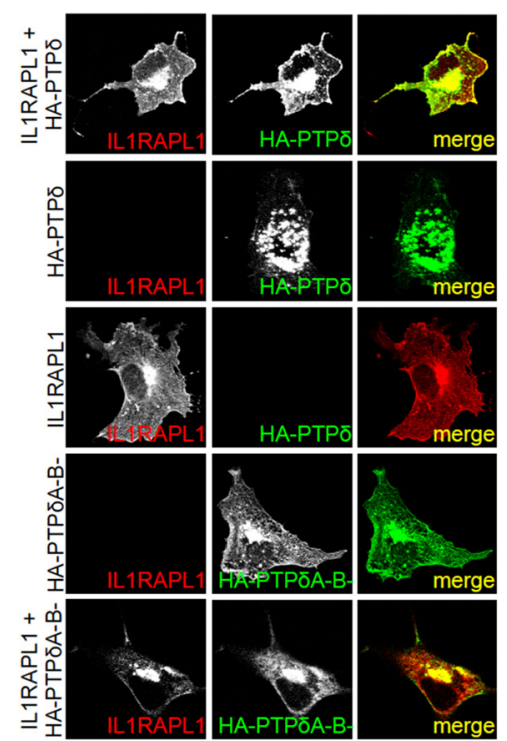

Figure 9. PTP $\delta$ recruitment to dendrites by IL1RAPL1 cis-interaction. $A$, Hippocampal neurons were transfected at DIV 11 with GFP, HA-IL1RAPL1, and IL1RAPL1 in combination with HA-PTP $\delta$ and HA-PTP $\delta$ A-B - (HA-PTP $\delta$ without miniexons A and B), and HA-TSPAN7. At DIV 14-15, live hippocampal neurons were subjected to a surface staining. Total (blue signal) and surface (red signal) staining using anti-HA tag antibody are shown. $\boldsymbol{B}$, The graph shows ratios of average intensity of surface HA signal per total HA signal measured for each neuron. All values represent mean \pm SEM. ${ }^{*} p<0.05$, compared with GFP +PTP $\delta$ condition (Student's $t$ test.). C, Lysates from COS-7 cells coexpressing the indicated IL1RAPL1 and HA-PTP $\delta$ constructs were subjected to immunoprecipitation assay using rabbit anti-HA or rabbit lgG antibody. Ten percent of the lysate used for the immunoprecipitation and immunoprecipitate proteins were detected after immunoblotting using goat anti-IL1RAPL1 and mouse anti-HA antibodies. D, The images show coclustering assay in COS-7-transfected and stained with the indicated constructs.

Consistent with the necessity of appropriate dendritic architecture for high-order brain functions (including learning and memory), abnormalities in dendrite architecture have been observed in a variety of neurodevelopmental, neurodegenerative, and neuropsychiatric disorders, such as schizophrenia, Down's syndrome, Angelman's syndrome, Rett's syndrome, and autism (Dierssen and Ramakers, 2006; Stuss et al., 2012; Miao et al., 2013; Blizinsky et al., 2016; Ori-McKenney et al., 2016; MartínezCerdeño, 2017).
Mutations in the IL1RAPL1 gene have been found in patients with ID or autism (Carrie et al., 1999; Piton et al., 2008). Also, even if IL1RAPL1 function has been strongly associated with excitatory synapse formation, the knock-down of IL1RAPL1 using specific miRNAs leads to a significant increase in both the number and the length of neurites (Piton et al., 2008). Furthermore, Gambino et al. (2007) have reported that the overexpression of IL1RAPL1 in PC12 cells decreases the NGF-induced neurite outgrowth. 
A
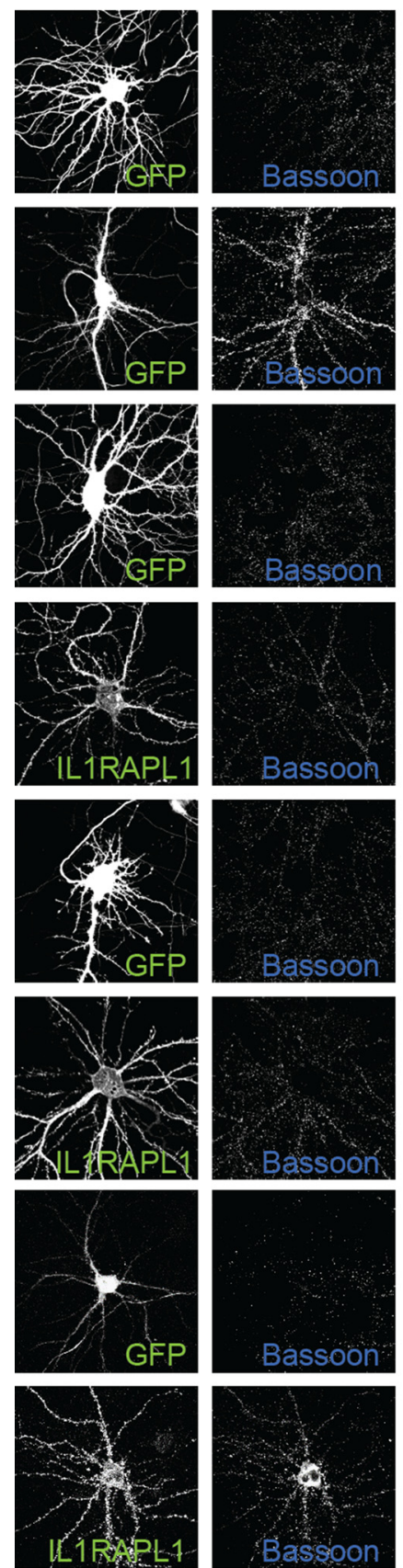
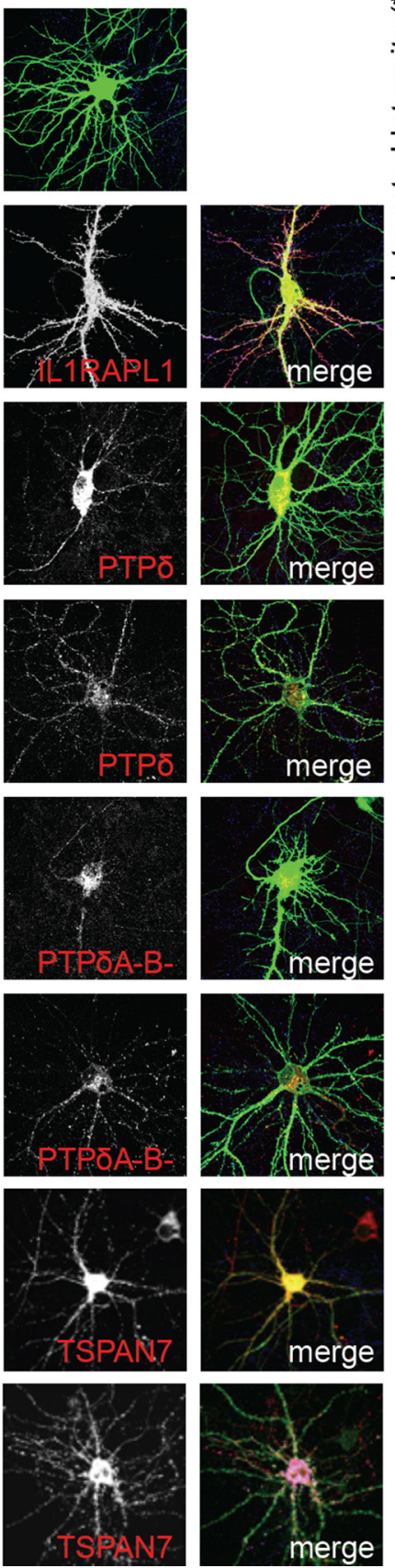
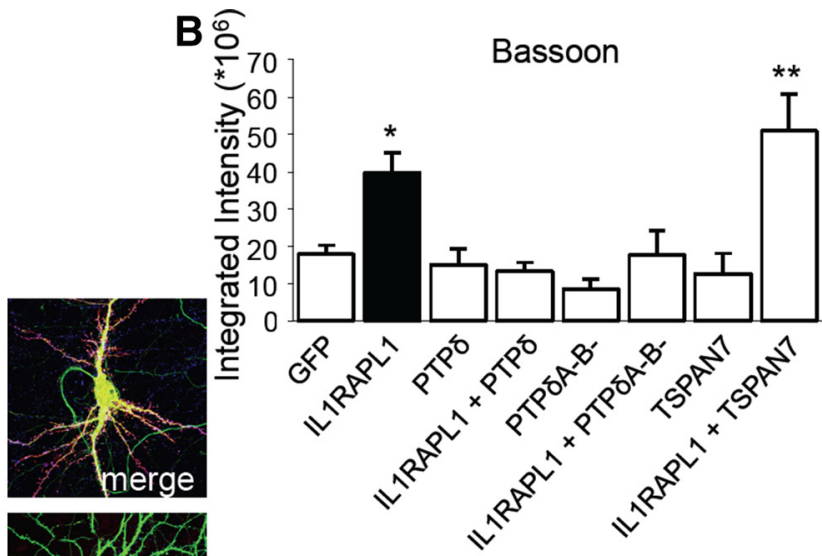

Figure 10. PTP $\delta$ and IL1RAPL1 cis-interaction blocks the ability of IL1RAPL1 to induce synaptogenesis. $\boldsymbol{A}$, Hippocampal neurons were transfected at DIV 11 with GFP, HA-IL1RAPL1, and IL1RAPL1 alone or in combination with HA-PTP $\delta$ or HA-PTP $\delta$ A-B - or HA-TSPAN7, then fixed at DIV 14-15 and stained with anti-HA, anti-IL1RAPL1, and anti-Bassoon antibody. $B$, The graph shows the quantification of Bassoon cluster intensity. All values show the mean \pm SEM of integrated intensity. Five to 10 neurons from three independent experiments for each condition were used. ${ }^{*} p<0.05$, ${ }^{* *} p<0.005$ vs GFP ANOVA followed by Dunnet's post hoc test.

Given the emerging role of IL1RAPL1 in neurite outgrowth, we decided to investigate its effect in vivo and in vitro.

We first observed an increased number of branching points in Ill rapl1-KO hippocampal neurons in CA1 and CA2. Meanwhile, the number of branching points of cortical neurons from WT and KO mice is comparable. These results suggest that the absence of IL1RAPL1 in vivo affects dendrite development in the hippocampus, but not in the cortex. However, importantly, we found a similar dendrite development alteration in hiPS cell-derived neurons obtained from a patient with a null mutation in the
IL1RAPL1 gene, indicating that this function is present also in human neurons, although our data are limited to only one patient and need to be further confirmed with cells obtained from other patients with similar deletion in IL1RAPL1.

Not surprisingly, the overexpression of IL1RAPL1 results in fewer branching points compared with control (GFP-expressing neurons) both in vitro and in vivo. By contrast, the overexpression of IL1RAPL1 mutants (including a single amino acid mutant C31R) affecting the extracellular domain function does not seem to affect arborization. Thus, our data indicate that the extracellu- 
lar part of IL1RAPL1 protein seems to be involved in dendrite arborization.

Given that the only known interactor of IL1RAPL1 extracellular domain is PTP $\delta$ and that the entire extracellular domain of PTP $\delta$ can promote cell adhesion and neurite outgrowth (Gonzalez-Brito and Bixby, 2006), we decided to explore whether their trans- synaptic interaction could be involved in the effect on dendrite arborization. Our data suggest that transsynaptic interaction between IL1RAPL1 and PTP $\delta$ is not involved in the IL1RAPL1-mediated effect on dendrite arborization simplification because (1) in young and synaptic immature neurons (at DIV 4), the overexpression of IL1RAPL1 leads to dendritic simplification, and (2) the shRNA-mediated decrease of PTP $\delta$ reduces the number of secondary dendrites and the total length of primary and secondary dendrites.

Given that the IL1RAPL1-PTP $\delta$ transsynaptic interaction seems not to be involved in this phenomenon, we tried to understand whether a possible cis-interaction between those proteins could explain the IL1RAPL1-mediated effect on dendrite arborization. As expected, overexpressed PTP $\delta$ in neurons is mostly localized in axons (Dunah et al., 2005; Takahashi et al., 2011). However, the co-overexpression with IL1RAPL1 redirects PTP $\delta$ to the surface membrane of dendrites (where IL1RAPL1 is localized), indicating that the two proteins can interact in cis-. Interestingly this cis-interaction blocks the effect of IL1RAPL1 on both dendrite simplification and recruitment of the excitatory presynaptic compartment.

The antagonistic effect of endogenous PTP $\delta$ might also be present because PTP $\delta$ silencing by shRNA mimics the effect of IL1RAPL1 overexpression, possibly because the absence of endogenous PTP $\delta$ releases the activity on dendrites of endogenous IL1RAPL1. Indeed, a recent paper (Shishikura et al., 2016) showed that the deletion of PTP $\delta$ interferes with dendrite development in Purkinje cells, thus suggesting that PTP $\delta$ is probably also expressed in dendrites of those cells.

However it's not clear why PTP $\delta$ without miniexons $\mathrm{A}$ and $\mathrm{B}(\mathrm{PTP} \delta \mathrm{A}-\mathrm{B}-$ ), which should not bind to IL1RAPL1, is also able to block IL1RAPL1 activity (Yoshida et al., 2011). It is possible that the role of the miniexons in the IL1RAPL1-PTP $\delta$ interaction is less important in cis- than in trans-, or that different interaction sites are important in cis-. However, PTP $\delta \mathrm{A}-\mathrm{B}-$ is also highly localized to dendrites and not further recruited to this compartment by the co-overexpression of IL1RAPL1.

If PTP $\delta$ is not involved in IL1RAPL1-induced neurite modifications, we wondered whether IL1RAPL1, through its extracel-
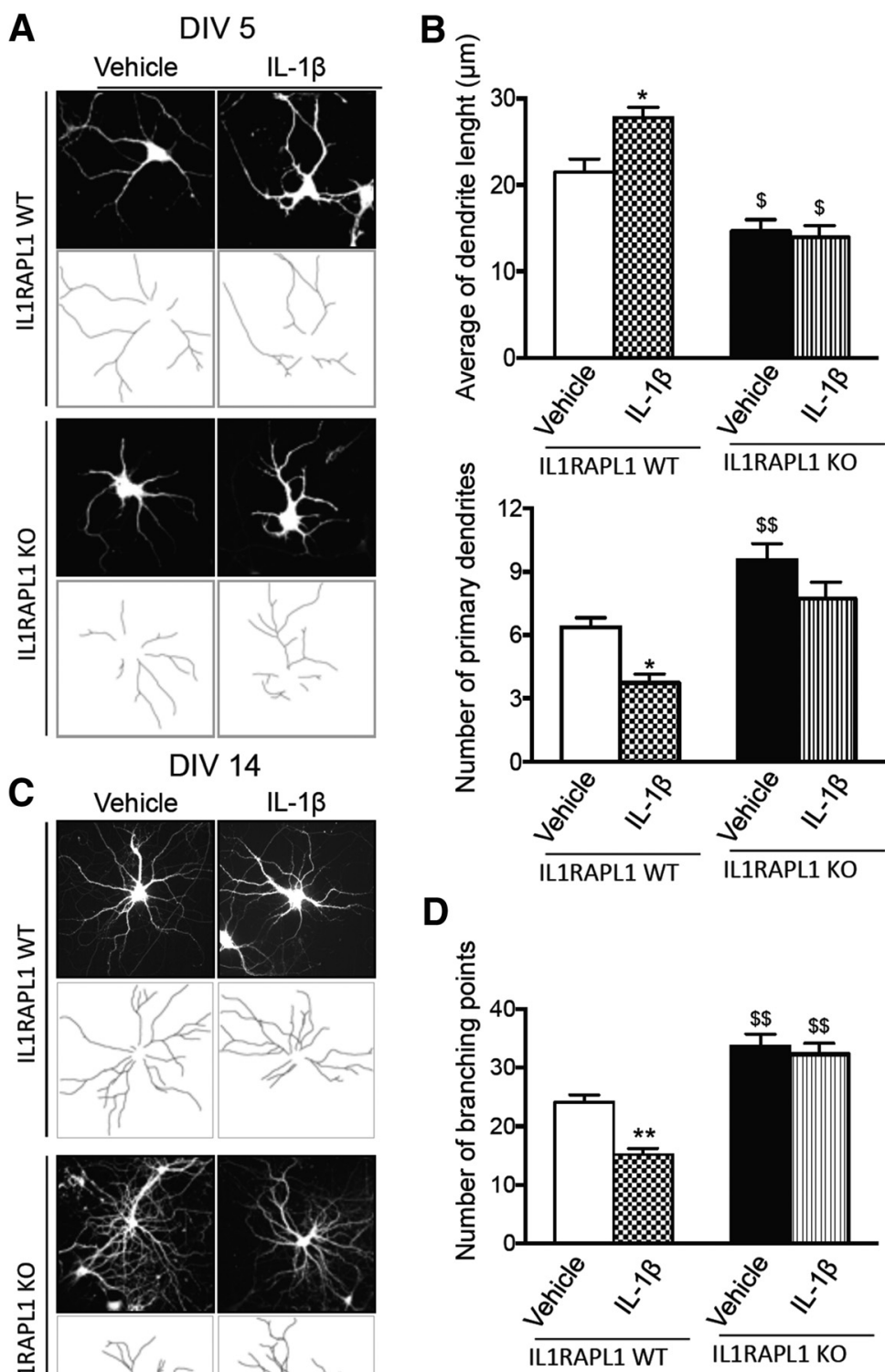

Figure 11. IL-1 $\beta$ regulation of dendrite morphology is mediated by IL1RAPL1. $\boldsymbol{A}$, Hippocampal neurons from WT and //1 rap/1-K0 mice were infected at DIV 1 with lentivirus expressing GFP and treated with $10 \mathrm{ng} / \mathrm{ml} \mathrm{IL-1} \beta$ or vehicle for $72 \mathrm{~h}$ before being fixed at DIV 5. GFP signal was used for the morphological analysis of the cells. $\boldsymbol{B}$, The graphs show the quantification of average dendrite length and total number of primary dendrites. Ten to 15 neurons were analyzed for each genotype and treatment in three independent experiments. All values represent mean \pm SEM. ${ }^{*} p<0.05$ vs vehicle, $\$<0.05, \$ \$ 0.005$ vs IL1RAPL1 WT vehicle, ANOVA followed by Dunnet's post hoc test. C, Hippocampal neurons from WT and /17rap/1-KO mice were infected at DIV 8 with lentivirus expressing GFP and treated with $10 \mathrm{ng} / \mathrm{ml} \mathrm{IL-1} \beta$ or vehicle for $72 \mathrm{~h}$ before being fixed at DIV 14 . GFP signal was used for the morphological analysis of the cells. $D$, Graphs show the quantification of branching points. Two to 15 neurons were analyzed for each genotype and treatment in three independent experiments. All values represent mean \pm SEM. ${ }^{* *} p<0.005$ vs vehicle, $\$$. $<0.005$ vs IL1RAPL1 WT vehicle, ANOVA followed by Dunnet's post hoc test.

lular domain, mediates the IL- $1 \beta$-induced changes in dendrite branching.

We tested IL- $1 \beta$ instead of other cytokines because we previously demonstrated that JNK activation by IL- $1 \beta$ in hippocampal neurons is also mediated by the presence of IL1RAPL1 (Pavlowsky et al., 2010b)

Interestingly we found that in cultured hippocampal neurons from Ill rapl1-KO mice, IL- $1 \beta$ was unable to modify dendrite morphology. In line with previous results, IL1RAPL1 is required for 
the IL- $1 \beta$-dependent signaling and modification of dendrite morphology.

The high level of IL- $1 \beta$ in the brain has been associated with cognitive alterations, such as ASD (Zerbo et al., 2014; Krakowiak et al., 2017). Our data suggest that the absence of IL1RAPL1 might also strongly reduce the effect of IL- $1 \beta$ on neurons and this can also be linked to alteration in cognitive functions. However, how IL1RAPL1 modulates the activity of IL- $1 \beta$ and its receptor remains to be determined even if our in vitro experiments suggest that the overexpression of IL1RAPL1 in neurons is sufficient to induce the activation of IL- $1 \beta$ receptors, assuming that the concentration of IL- $1 \beta$ is low in the cultured medium. On the other hand, we cannot totally exclude the possibility that one or more other IL1RAPL1 interactors are involved in the effect on dendrite morphology. Those proteins should have a primary role in hippocampal function and development.

Our studies and those of Yasumura et al. (2014) behavioral studies on Il1rapl1-KO mice indicate that the absence of this protein does not affect the sensory abilities and the innate behavior of mice.

Interestingly memory function tests show that Il1 rapl1-KO mice have normal performance in tasks, depending on both cortical and hippocampal areas (passive avoidance test), but present impairment in spatial memory evaluated through T-maze, Morris water-maze, and radial-maze tasks and had a clear deficit in a hippocampus-dependent fear-conditioning memory task. Similar behavioral deficits were described by Yasumura et al. (2014) and Zhang et al. (2015). Thus, IL1RAPL1 mice have serious difficulty retaining spatial working memory and accomplishing in fear-conditioning memory tasks, suggesting an essentially hippocampal-altered activity. In conclusion, the present study and others with mutant mice (Gambino et al., 2009; Houbaert et al., 2013; Yasumura et al., 2014) revealed that the ablation of Il1 rapl1 affects diverse brain functions, including learning, memory, and anxiety, and some repetitive behavior. However, the social abilities seem either not to be altered, as in our study, or increased, as in the mice analyzed by Yasumura et al. (2014), indicating that these genetically modified mice represent a model mostly, if not exclusively for ID, and not for ASD.

Similarly, human patients with IL1RAPL1 mutations are characterized by strong ID and minor ASD symptoms (Carrie et al., 1999; Tabolacci et al., 2006; Bhat et al., 2008; Nawara et al., 2008; Piton et al., 2008; Behnecke et al., 2011; Franek et al., 2011; Youngs et al., 2012; Barone et al., 2013). Our study demonstrates how neural circuits responsible for these mental disorders are affected by IL1RAPL1 mutations. IL1RAPL1 induces excitatory synapse formation by trans-synaptic interaction with PTP $\delta$ (Valnegri et al., 2011b; Yoshida et al., 2011), by recruiting PSD-95 at synapses via JNK activation (Pavlowsky et al., 2010a), and by controlling AMPA receptor trafficking via the interaction with Mcf2l (Hayashi et al., 2013). These observations strongly suggest that deletion of Ill rapll causes the imbalance of excitation and inhibition in multiple brain circuits. The data in this paper indicate that the deletion of Ill rapl1, besides altering synapses, also alters dendrite development by increasing the complexity. This effect seems specific, at least in mice and in vivo, to the hippocampus. We can speculate that these specific synaptic and dendritic alterations are responsible for the cognitive impairment observed in mice and in patients.

On the other hand, the abnormalities in dendrite architecture we describe here are not the same as those described in other ASD and ID disorders, where a reduction of dendrite complexity was usually observed. To our knowledge such increase in dendrite complexity has been already described once in the striatal neurons of a Shank3-KO mice (Peça et al., 2011). Thus, even if it's still unclear whether changes in dendrite morphogenesis contribute to disease pathogenesis or are simply a sign of altered neuronal connectivity, our data suggest that increased dendrite complexity could be also associated with some forms of ID.

Finally since our data indicate that neurons lacking IL1RAPL1 fail to respond to IL- $1 \beta$-mediated effects on dendrites, elucidation of the functional role of this gene on cytokine activity during brain development will help identify potential drug targets to treat ID patients carrying IL1RAPL1 gene mutations.

\section{References}

Arikkath J (2012) Molecular mechanisms of dendrite morphogenesis. Front Cell Neurosci 6:61. CrossRef Medline

Barone C, Bianca S, Luciano D, Di Benedetto D, Vinci M, Fichera M (2013) Intragenic ILRAPL1 deletion in a male patient with intellectual disability, mild dysmorphic signs, deafness, and behavioral problems. Am J Med Genet A 161A:1381-1385. CrossRef Medline

Bassani S, Cingolani LA, Valnegri P, Folci A, Zapata J, Gianfelice A, Sala C, Goda Y, Passafaro M (2012) The X-linked intellectual disability protein TSPAN7 regulates excitatory synapse development and AMPAR trafficking. Neuron 73:1143-1158. CrossRef Medline

Behnecke A, Hinderhofer K, Bartsch O, Nümann A, Ipach ML, Damatova N, Haaf T, Dufke A, Riess O, Moog U (2011) Intragenic deletions of IL1RAPL1: report of two cases and review of the literature. Am J Med Genet A 155A:372-379. CrossRef Medline

Bhat SS, Ladd S, Grass F, Spence JE, Brasington CK, Simensen RJ, Schwartz CE, Dupont BR, Stevenson RE, Srivastava AK (2008) Disruption of the IL1RAPL1 gene associated with a pericentromeric inversion of the $X$ chromosome in a patient with mental retardation and autism. Clin Genet 73:94-96. CrossRef Medline

Blizinsky KD, Diaz-Castro B, Forrest MP, Schürmann B, Bach AP, Martinde-Saavedra MD, Wang L, Csernansky JG, Duan J, Penzes P (2016) Reversal of dendritic phenotypes in 16p11.2 microduplication mouse model neurons by pharmacological targeting of a network hub. Proc Natl Acad Sci U S A 113:8520-8525. CrossRef Medline

Braida D, Sacerdote $\mathrm{P}$, Panerai $\mathrm{AE}$, Bianchi $\mathrm{M}$, Aloisi AM, Iosuè $\mathrm{S}$, Sala $\mathrm{M}$ (2004) Cognitive function in young and adult IL (interleukin)-6 deficient mice. Behav Brain Res 153:423-429. CrossRef Medline

Braida D, Limonta V, Malabarba L, Zani A, Sala M (2007) 5-HT1A receptors are involved in the anxiolytic effect of Delta9-tetrahydrocannabinol and AM 404, the anandamide transport inhibitor, in Sprague-Dawley rats. Eur J Pharmacol 555:156-163. CrossRef Medline

Bruno KJ, Freet CS, Twining RC, Egami K, Grigson PS, Hess EJ (2007) Abnormal latent inhibition and impulsivity in coloboma mice, a model of ADHD. Neurobiol Dis 25:206-216. CrossRef Medline

Carlessi L, Fusar Poli E, Bechi G, Mantegazza M, Pascucci B, Narciso L, Dogliotti E, Sala C, Verpelli C, Lecis D, Delia D (2014) Functional and molecular defects of hiPSC-derived neurons from patients with ATM deficiency. Cell Death Dis 5:e1342. CrossRef Medline

Carrie A, Jun L, Bienvenu T, Vinet MC, McDonell N, Couvert P, Zemni R, Cardona A, Van Buggenhout G, Frints S, Hamel B, Moraine C, Ropers HH, Strom T, Howell GR, Whittaker A, Ross MT, Kahn A, Fryns JP, Beldjord C, et al (1999) A new member of the IL-1 receptor family highly expressed in hippocampus and involved in X-linked mental retardation. Nat Genet 23:25-31. CrossRef Medline

Chechlacz M, Gleeson JG (2003) Is mental retardation a defect of synapse structure and function? Pediatr Neurol 29:11-17. CrossRef Medline

dal Maschio M, Ghezzi D, Bony G, Alabastri A, Deidda G, Brondi M, Sato SS, Zaccaria RP, Di Fabrizio E, Ratto GM, Cancedda L (2012) Highperformance and site-directed in utero electroporation by a tripleelectrode probe. Nat Commun 3:960. CrossRef Medline

Deacon RM (2006) Assessing nest building in mice. Nat Protoc 1:11171119. CrossRef Medline

Dierssen M, Ramakers GJ (2006) Dendritic pathology in mental retardation: from molecular genetics to neurobiology. Genes Brain Behav 5 [Suppl 2]:48-60. CrossRef Medline

Dunah AW, Hueske E, Wyszynski M, Hoogenraad CC, Jaworski J, Pak DT, Simonetta A, Liu G, Sheng M (2005) LAR receptor protein tyrosine 
phosphatases in the development and maintenance of excitatory synapses. Nat Neurosci 8:458-467. CrossRef Medline

Foa L, Rajan I, Haas K, Wu GY, Brakeman P, Worley P, Cline H (2001) The scaffold protein, Homer 1b/c, regulates axon pathfinding in the central nervous system in vivo. Nat Neurosci 4:499-506. CrossRef Medline

Franek KJ, Butler J, Johnson J, Simensen R, Friez MJ, Bartel F, Moss T, DuPont B, Berry K, Bauman M, Skinner C, Stevenson RE, Schwartz CE (2011) Deletion of the immunoglobulin domain of IL1RAPL1 results in nonsyndromic X-linked intellectual disability associated with behavioral problems and mild dysmorphism. Am J Med Genet A 155A:1109-1114. CrossRef Medline

Gambino F, Pavlowsky A, Béglé A, Dupont JL, Bahi N, Courjaret R, Gardette R, Hadjkacem H, Skala H, Poulain B, Chelly J, Vitale N, Humeau Y (2007) IL1-receptor accessory protein-like 1 (IL1RAPL1), a protein involved in cognitive functions, regulates N-type Ca2+-channel and neurite elongation. Proc Natl Acad Sci U S A 104:9063-9068. CrossRef Medline

Gambino F, Kneib M, Pavlowsky A, Skala H, Heitz S, Vitale N, Poulain B, Khelfaoui M, Chelly J, Billuart P, Humeau Y (2009) IL1RAPL1 controls inhibitory networks during cerebellar development in mice. Eur J Neurosci 30:1476-1486. CrossRef Medline

Gerrow K, Romorini S, Nabi SM, Colicos MA, Sala C, El-Husseini A (2006) A preformed complex of postsynaptic proteins is involved in excitatory synapse development. Neuron 49:547-562. CrossRef Medline

Gilmore JH, Fredrik Jarskog L, Vadlamudi S, Lauder JM (2004) Prenatal infection and risk for schizophrenia: IL- $1 \beta$, IL-6, and TNF $\alpha$ inhibit cortical neuron dendrite development. Neuropsychopharmacology 29: 1221-1229. Medline

Glaser EM, Van der Loos H (1981) Analysis of thick brain sections by obverse-reverse computer microscopy: application of a new, high clarity Golgi-Nissl stain. J Neurosci Methods 4:117-125. CrossRef Medline

Gonzalez-Brito MR, Bixby JL (2006) Differential activities in adhesion and neurite growth of fibronectin type III repeats in the PTP-delta extracellular domain. Int J Dev Neurosci 24:425-429. CrossRef Medline

Hayashi MK, Tang C, Verpelli C, Narayanan R, Stearns MH, Xu RM, Li H, Sala C, Hayashi Y (2009) The postsynaptic density proteins Homer and Shank form a polymeric network structure. Cell 137:159-171. CrossRef Medline

Hayashi T, Yoshida T, Ra M, Taguchi R, Mishina M (2013) IL1RAPL1 associated with mental retardation and autism regulates the formation and stabilization of glutamatergic synapses of cortical neurons through RhoA signaling pathway. PLoS One 8:e66254. CrossRef Medline

Houbaert X, Zhang CL, Gambino F, Lepleux M, Deshors M, Normand E, Levet F, Ramos M, Billuart P, Chelly J, Herzog E, Humeau Y (2013) Target-specific vulnerability of excitatory synapses leads to deficits in associative memory in a model of intellectual disorder. J Neurosci 33: 13805-13819. CrossRef Medline

Krakowiak P, Goines PE, Tancredi DJ, Ashwood P, Hansen RL, HertzPicciotto I, Van de Water J (2017) Neonatal cytokine profiles associated with autism spectrum disorder. Biol Psychiatry 81:442-451. CrossRef Medline

Kwon SK, Woo J, Kim SY, Kim H, Kim E (2010) Trans-synaptic adhesions between netrin-G ligand-3 (NGL-3) and receptor tyrosine phosphatases LAR, protein-tyrosine phosphatase delta (PTPdelta), and PTPsigma via specific domains regulate excitatory synapse formation. J Biol Chem 285: 13966-13978. CrossRef Medline

Livak KJ, Schmittgen TD (2001) Analysis of relative gene expression data using real-time quantitative PCR and the 2(-Delta Delta C(T)) Method. Methods 25:402-408. CrossRef Medline

Lois C, Hong EJ, Pease S, Brown EJ, Baltimore D (2002) Germline transmission and tissue-specific expression of transgenes delivered by lentiviral vectors. Science 295:868-872. CrossRef Medline

Martínez-Cerdeño V (2017) Dendrite and spine modifications in autism and related neurodevelopmental disorders in patients and animal models. Dev Neurobiol 77:393-404. CrossRef Medline

McAllister AK (2000) Cellular and molecular mechanisms of dendrite growth. Cereb Cortex 10:963-973. CrossRef Medline

McFarlane HG, Kusek GK, Yang M, Phoenix JL, Bolivar VJ, Crawley JN (2008) Autism-like behavioral phenotypes in BTBR T+tf/J mice. Genes Brain Behav 7:152-163. CrossRef Medline

Meijering E, Jacob M, Sarria JC, Steiner P, Hirling H, Unser M (2004) De- sign and validation of a tool for neurite tracing and analysis in fluorescence microscopy images. Cytometry A 58:167-176. Medline

Miao S, Chen R, Ye J, Tan GH, Li S, Zhang J, Jiang YH, Xiong ZQ (2013) The Angelman syndrome protein Ube3a is required for polarized dendrite morphogenesis in pyramidal neurons. J Neurosci 33:327-333. CrossRef Medline

Mishra A, Kim HJ, Shin AH, Thayer SA (2012) Synapse loss induced by interleukin- $1 \beta$ requires pre- and post-synaptic mechanisms. J Neuroimmune Pharmacol 7:571-578. CrossRef Medline

Morris R (1984) Developments of a water-maze procedure for studying spatial learning in the rat. J Neurosci Methods 11:47-60. CrossRef Medline

Mosienko V, Bert B, Beis D, Matthes S, Fink H, Bader M, Alenina N (2012) Exaggerated aggression and decreased anxiety in mice deficient in brain serotonin. Transl Psychiatry 2:e122. CrossRef Medline

Moy SS, Nadler JJ, Perez A, Barbaro RP, Johns JM, Magnuson TR, Piven J, Crawley JN (2004) Sociability and preference for social novelty in five inbred strains: an approach to assess autistic-like behavior in mice. Genes Brain Behav 3:287-302. CrossRef Medline

Naldini L, Blömer U, Gallay P, Ory D, Mulligan R, Gage FH, Verma IM, Trono D (1996) In vivo gene delivery and stable transduction of nondividing cells by a lentiviral vector. Science 272:263-267. CrossRef Medline

Nawara M, Klapecki J, Borg K, Jurek M, Moreno S, Tryfon J, Bal J, Chelly J, Mazurczak T (2008) Novel mutation of IL1RAPL1 gene in a nonspecific X-linked mental retardation (MRX) family. Am J Med Genet A 146A: 3167-3172. CrossRef Medline

Newey SE, Velamoor V, Govek EE, Van Aelst L (2005) Rho GTPases, dendritic structure, and mental retardation. J Neurobiol 64:58-74. CrossRef Medline

Ori-McKenney KM, McKenney RJ, Huang HH, Li T, Meltzer S, Jan LY, Vale RD, Wiita AP, Jan YN (2016) Phosphorylation of $\beta$-tubulin by the Down syndrome kinase, minibrain/DYRK1a, regulates microtubule dynamics and dendrite morphogenesis. Neuron 90:551-563. CrossRef Medline

Pan H, Xia LZ (2008) Efficient object recognition using boundary representation and wavelet neural network. IEEE Trans Neural Netw 19:21322149. CrossRef Medline

Pavlowsky A, Gianfelice A, Pallotto M, Zanchi A, Vara H, Khelfaoui M, Valnegri P, Rezai X, Bassani S, Brambilla D, Kumpost J, Blahos J, Roux MJ, Humeau Y, Chelly J, Passafaro M, Giustetto M, Billuart P, Sala C (2010a) A postsynaptic signaling pathway that may account for the cognitive defect due to IL1RAPL1 mutation. Curr Biol 20:103-115. CrossRef Medline

Pavlowsky A, Zanchi A, Pallotto M, Giustetto M, Chelly J, Sala C, Billuart P (2010b) Neuronal JNK pathway activation by IL-1 is mediated through IL1RAPL1, a protein required for development of cognitive functions. Commun Integr Biol 3:245-247. CrossRef Medline

Peça J, Feliciano C, Ting JT, Wang W, Wells MF, Venkatraman TN, Lascola CD, Fu Z, Feng G (2011) Shank3 mutant mice display autistic-like behaviours and striatal dysfunction. Nature 472:437-442. CrossRef Medline

Piton A, Michaud JL, Peng H, Aradhya S, Gauthier J, Mottron L, Champagne $\mathrm{N}$, Lafrenière RG, Hamdan FF, Joober R, Fombonne E, Marineau C, Cossette P, Dubé MP, Haghighi P, Drapeau P, Barker PA, Carbonetto S, Rouleau GA (2008) Mutations in the calcium-related gene IL1RAPL1 are associated with autism. Hum Mol Genet 17:3965-3974. CrossRef Medline

Ramos-Brossier M, Montani C, Lebrun N, Gritti L, Martin C, SeminatoreNole C, Toussaint A, Moreno S, Poirier K, Dorseuil O, Chelly J, Hackett A, Gecz J, Bieth E, Faudet A, Heron D, Frank Kooy R, Loeys B, Humeau Y, Sala C, et al (2015) Novel IL1RAPL1 mutations associated with intellectual disability impair synaptogenesis. Hum Mol Genet 24:1106-1118. CrossRef Medline

Romorini S, Piccoli G, Jiang M, Grossano P, Tonna N, Passafaro M, Zhang M, Sala C (2004) A functional role of postsynaptic density-95-guanylate kinase-associated protein complex in regulating shank assembly and stability to synapses. J Neurosci 24:9391-9404. CrossRef Medline

Sala M, Braida D, Lentini D, Busnelli M, Bulgheroni E, Capurro V, Finardi A, Donzelli A, Pattini L, Rubino T, Parolaro D, Nishimori K, Parenti M, Chini B (2011) Pharmacologic rescue of impaired cognitive flexibility, social deficits, increased aggression, and seizure susceptibility in oxytocin receptor null mice: a neurobehavioral model of autism. Biol Psychiatry 69:875-882. CrossRef Medline

Sala C, Segal M (2014) Dendritic spines: the locus of structural and functional plasticity. Physiol Rev 94:141-188. CrossRef Medline

Shishikura M, Nakamura F, Yamashita N, Uetani N, Iwakura Y, Goshima Y 
(2016) Expression of receptor protein tyrosine phosphatase $\delta$, PTP $\delta$, in mouse central nervous system. Brain Res 1642:244-254. CrossRef Medline

Stuart GJ, Spruston N (2015) Dendritic integration: 60 years of progress. Nat Neurosci 18:1713-1721. CrossRef Medline

Stuss DP, Boyd JD, Levin DB, Delaney KR (2012) MeCP2 mutation results in compartment-specific reductions in dendritic branching and spine density in layer 5 motor cortical neurons of YFP-H mice. PLoS One 7:e31896. CrossRef Medline

Tabolacci E, Pomponi MG, Pietrobono R, Terracciano A, Chiurazzi P, Neri G (2006) A truncating mutation in the IL1RAPL1 gene is responsible for X-linked mental retardation in the MRX21 family. Am J Med Genet A 140:482-487. Medline

Takahashi H, Arstikaitis P, Prasad T, Bartlett TE, Wang YT, Murphy TH, Craig AM (2011) Postsynaptic TrkC and presynaptic PTP $\sigma$ function as a bidirectional excitatory synaptic organizing complex. Neuron 69:287303. CrossRef Medline

Takahashi K, Yamanaka S (2006) Induction of pluripotent stem cells from mouse embryonic and adult fibroblast cultures by defined factors. Cell 126:663-676. CrossRef Medline

Tordjman S, Carlier M, Cohen D, Cesselin F, Bourgoin S, Colas-Linhart N, Petiet A, Perez-Diaz F, Hamon M, Roubertoux PL (2003) Aggression and the three opioid families (endorphins, enkephalins, and dynorphins) in mice. Behav Genet 33:529-536. CrossRef Medline

Turner JR, Castellano LM, Blendy JA (2010) Nicotinic partial agonists varenicline and sazetidine-A have differential effects on affective behavior. J Pharmacol Exp Ther 334:665-672. CrossRef Medline

Valnegri P, Khelfaoui M, Dorseuil O, Bassani S, Lagneaux C, Gianfelice A, Benfante R, Chelly J, Billuart P, Sala C, Passafaro M (2011a) A circadian clock in hippocampus is regulated by interaction between oligophrenin-1 and Rev-erb alpha. Nat Neurosci 14:1293-1301. CrossRef Medline

Valnegri P, Montrasio C, Brambilla D, Ko J, Passafaro M, Sala C (2011b) The X-linked intellectual disability protein IL1RAPL1 regulates excitatory synapse formation by binding PTP delta and RhoGAP2. Hum Mol Genet 20:4797-4809. CrossRef Medline

Valnegri P, Puram SV, Bonni A (2015) Regulation of dendrite morphogenesis by extrinsic cues. Trends Neurosci 38:439-447. CrossRef Medline

Verpelli C, Piccoli G, Zibetti C, Zanchi A, Gardoni F, Huang K, Brambilla D, Di Luca M, Battaglioli E, Sala C (2010) Synaptic activity controls den- dritic spine morphology by modulating eEF2-dependent BDNF synthesis. J Neurosci 30:5830-5842. CrossRef Medline

Verpelli C, Carlessi L, Bechi G, Fusar Poli E, Orellana D, Heise C, Franceschetti S, Mantegazza R, Mantegazza M, Delia D, Sala C (2013) Comparative neuronal differentiation of self-renewing neural progenitor cell lines obtained from human induced pluripotent stem cells. Front Cell Neurosci 7:175. CrossRef Medline

Xiao Z, Peng J, Yang L, Kong H, Yin F (2015) Interleukin- $1 \beta$ plays a role in the pathogenesis of mesial temporal lobe epilepsy through the PI3K/Akt/ mTOR signaling pathway in hippocampal neurons. J Neuroimmunol 282:110-117. CrossRef Medline

Yasumura M, Yoshida T, Yamazaki M, Abe M, Natsume R, Kanno K, Uemura T, Takao K, Sakimura K, Kikusui T, Miyakawa T, Mishina M (2014) IL1RAPL1 knockout mice show spine density decrease, learning deficiency, hyperactivity and reduced anxiety-like behaviours. Sci Rep 4:6613. CrossRef Medline

Yoshida T, Yasumura M, Uemura T, Lee SJ, Ra M, Taguchi R, Iwakura Y, Mishina M (2011) IL-1 receptor accessory protein-like 1 associated with mental retardation and autism mediates synapse formation by transsynaptic interaction with protein tyrosine phosphatase $\delta$. J Neurosci 31: 13485-13499. CrossRef Medline

Youngs EL, Henkhaus R, Hellings JA, Butler MG (2012) IL1RAPL1 gene deletion as a cause of $\mathrm{X}$-linked intellectual disability and dysmorphic features. Eur J Med Genet 55:32-36. CrossRef Medline

Zerbo O, Yoshida C, Grether JK, Van de Water J, Ashwood P, Delorenze GN, Hansen RL, Kharrazi M, Croen LA (2014) Neonatal cytokines and chemokines and risk of autism spectrum disorder: the early markers for autism (EMA) study: a case-control study. J Neuroinflammation 11:113. CrossRef Medline

Zhang CL, Houbaert X, Lepleux M, Deshors M, Normand E, Gambino F, Herzog E, Humeau Y (2015) The hippocampo-amygdala control of contextual fear expression is affected in a model of intellectual disability. Brain Struct Funct 220:3673-3682. CrossRef Medline

Zhang H, Zhang SB, Zhang QQ, Liu M, He XY, Zou Z, Sun HJ, You ZD, Shi XY (2013) Rescue of cAMP response element-binding protein signaling reversed spatial memory retention impairments induced by subanesthetic dose of propofol. CNS Neurosci Ther 19:484-493. CrossRef Medline 